Illinois State University

ISU ReD: Research and eData

Theses and Dissertations

3-6-2014

\title{
Tammy Rae Carland's Queer Riot Grrrl Zine "I (heart) Amy Carter": A World of Public Intimacy
}

Annah-Marie Rostowsky

Illinois State University, annahmarie.r@gmail.com

Follow this and additional works at: https://ir.library.illinoisstate.edu/etd

Part of the American Literature Commons, History of Art, Architecture, and Archaeology Commons, Literature in English, North America Commons, and the Women's Studies Commons

\section{Recommended Citation}

Rostowsky, Annah-Marie, "Tammy Rae Carland's Queer Riot Grrrl Zine "I (heart) Amy Carter": A World of Public Intimacy" (2014). Theses and Dissertations. 171.

https://ir.library.illinoisstate.edu/etd/171

This Thesis is brought to you for free and open access by ISU ReD: Research and eData. It has been accepted for inclusion in Theses and Dissertations by an authorized administrator of ISU ReD: Research and eData. For more information, please contact ISUReD@ilstu.edu. 
TAMMY RAE CARLAND'S QUEER RIOT GRRRL ZINE

\title{
I AMY CARTER: A WORLD OF PUBLIC INTIMACY
}

\author{
Annah-Marie Rostowsky
}

122 Pages

August 2014

This thesis analyzes Tammy Rae Carland's queer Riot Grrrl zine $I \vee$ Amy Carter as a counterpublic sphere engendered by acts of public intimacy that make visible the intersectional complexities of gender, sexuality, class, and race that insidious traumas continually work to conceal. It looks to Ann Cvetkovich's inquiries into the positive aspects of public cultures in the book An Archive of Feelings: Trauma, Sexuality, and Lesbian Public Cultures (2006) as well as Mimi Thi Nguyen's investigation of the Riot Grrrl race crisis in the article "Riot Grrrl, Race, and Revival" (2012) as frameworks to critique Carland's visual and textual articulations of the consequences of insidious traumas. It argues that Carland's contributions to Riot Grrrl's world of public intimacy are distinct from those of many other Riot Grrrls and, as such, corroborate Cvetkovich's position that acts of public intimacy are capable of producing positive effects.

Ultimately, it is a simultaneous reading of Carland's conception of her world and its associated politics during her formative years, an examination of the relationship between Carland's textual expressions and what she presents visually in $I \vee$ Amy Carter, as well as a critique of her contemporary culture. 
TAMMY RAE CARLAND'S QUEER RIOT GRRRL ZINE

$I \bullet A M Y$ CARTER: A WORLD OF PUBLIC INTIMACY

ANNAH-MARIE ROSTOWSKY

A Thesis Submitted in Partial

Fulfillment of the Requirements

for the Degree of

MASTER OF ARTS

School of Art

ILLINOIS STATE UNIVERSITY

2014 
(C) 2014 Annah-Marie Rostowsky 
TAMMY RAE CARLAND'S QUEER RIOT GRRRL ZINE

\title{
I $\bullet$ AMY CARTER: A WORLD OF PUBLIC INTIMACY
}

\author{
ANNAH-MARIE ROSTOWSKY
}

COMMITTEE MEMBERS:

Melissa Johnson, Chair

Elisabeth R. Friedman

Alison Bailey 


\section{ACKNOWLEDGMENTS}

This thesis would not have been possible if it were not for the support of a number of extraordinary people in my life and I'll be damned if I don't name every last one of them.

First and foremost, I have to extend my utmost gratitude to my incredible thesis committee, Drs. Melissa Johnson, Elisabeth Friedman, and Alison Bailey. I feel so fortunate to have had your support when I chose to approach such an untraditional topic for academic study. I have grown so much throughout this process and it is all because of your invaluable encouragement and guidance, for which I will be forever grateful. It has been an absolute honor, privilege, and pleasure to work so closely with you three, brilliant women.

To my partner-in-crime, Steve. Your love, support, and ridiculous sense of humor have been the most amazing gifts. Thank you for taking care of me and making sure I have had plenty of reasons to laugh. I love you forever.

To my Carabajals, Rostowskys, and other Jarochs. My moms and dads, Patti, Steve, Jorge, and Claudia; my siblings, Alex, Cameron, Chandler, Ava, and Audrey; and my in-laws and beagle, Caryn, Jim, and Buzz. In one way or another you've supported me through this process and I am so appreciative. You are all wonderful and I love you eternally. 
To Riot Grrrl. I didn't recognize it until twenty years after the fact, but this movement is the spark that ignited the woman and feminist I am today. Thank you for encouraging me to instigate verbal altercations with people who told me I couldn't do something because I am a girl. And thank you for inspiring my kick-ass fifth grade fashion.

To Tammy Rae Carland. It is pretty incredible that of all the Riot Grrrl zines out there I chose to write about $I \vee$ Amy Carter. Even after two decades have passed, both you and your zine are still inspiring generations of feminists and scholars. You should be proud. Thank you for creating something that resonated so deeply within me. I didn't think many families like ours existed and I don't feel alone anymore. Just so you know, you are my Amy Carter. So, if we ever meet, don't be freaked out if I get emotional.

Finally, I have to single out my amazing mother. There have been any number of positive influences in my life but yours will always be the most significant. You have shown me that even though life can be unjustifiably cruel, there is always beauty to be found. Instead of succumbing to the seemingly endless battles life has thrown at you, you have harnessed their power making you a force to be reckoned with. You are the strongest person I know, and you are also the most shining example of limitless love. Rest assured that these traits are forever embedded into the hearts of your children. Thank you, Mom, for everything you have endured. I would not have even had the chance to write this thesis had you not fought to give me a better life every step of the way. I love you.

A.M.R. 


\section{CONTENTS}

Page

ACKNOWLEDGMENTS

CONTENTS

\section{CHAPTER}

I. INTRODUCTION: "SOME HELPFUL HINTS FOR A LITTLE R + R" 1

The Shift from Essentialist to Intersectional Feminism 5

"SOME HELPFUL HINTS FOR A LITTLE R + R (RAGE + RESISTANCE)" $\quad 8$

Riot Grrrl's Enduring Legacy 11

Thesis Overview 14

II. ON GIRL LOVE AND PUBLIC INTIMACY 19

Riot Grrrl's World of Public Intimacy 20

Ann Cvetkovich Explores the Positive Possibilities of Public Intimacy 22

Trauma Beyond Clinical Terms 23

Insidious Traumas 25

Mimi Thi Nguyen Critiques Riot Grrrl's World of Public Intimacy 26

III. THE GENESIS OF I • AMY CARTER 32

Part I: From Punk to "Postfeminism" 32

Punk's Cut-and-Paste Identity 33

Hardcore Punk's Hardcore Aggression 34 
"Riot = Not Quiet": Grrrls Refuse

to be Silenced 38

Queercore Unites LGBT Punks 39

The Future of Feminism in the 1990s 43

The Rise and Fall of Women's Rights

from the 1970s-1990s 45

The Reagan Administration Initiates a Rigid

Neo-Conservative Environment 47

The Perpetuation of Postfeminism 52

Part II: Tammy Rae Carland's Personal History 54

A Brief Biography 55

"(the puddle under the table)" 57

Tammy Rae Carland, Identity, and I $\bullet$ Amy Carter $\quad 60$

IV. I $\quad$ AMY CARTER AS A COUNTERPUBLIC SPHERE 64

Part I: "FUCK YOUR GENDER": I $\bullet$ Amy Carter, Gender, and Sexuality 67

$I \vee$ Amy Carter's Visual Representation of Gender and Sexuality $\quad 68$

"The Truth is..." 69

Reclaiming Derogatory Terminology 73

Embracing Tabloid Trash 75

"BANNED IN CANADA": Reclaiming (Queer) Sexual Pleasure 77

"GIRL TALK": Reclaiming the Authority of Vulgar Vaginas

Part II: “If You're Dissin' The Sisters You Ain't Fighting

The Power!!": I Amy Carter and Race 83

Problems with Proximity 84

Acknowledging Race through Support and Statistics $\quad 86$

Approaching Race through Appropriated Academic Quotations

Cecilia Dougherty Reviews Bad Girls West 92

Co-opting Black Imagery

94 
Part III: "REFLECTIONS OF A STUPID SLUT": I $\bullet$ Amy

Carter and Class

The (In)Visibility of Welfare-Dependent Women

98

Expectations of the Poor

101

Visual Representations of Class

V. EPILOGUE

Thesis Goals, Conclusions, and Future Projects

The Significance of Zines as Alternative Press

Perpetuating the Discussion of Carland's Contemporary Social Issues and Broadening the Discourse on Riot Grrrl Culture

Future Directions for Analyzing Riot Grrrl Culture and $I \bullet$ Amy Carter

Final Thoughts 


\section{CHAPTER I}

\section{INTRODUCTION: "SOME HELPFUL HINTS FOR A LITTLE R + R”}

On December 5, 1992, Tammy Rae Carland launched the first of five issues of her queer Riot Grrrl zine $I \bullet$ Amy Carter. Today Carland is a practicing artist who is best known for her photographic works; but for the year-and-a-half of $I \bullet$ Amy Carter's production - the centralized focus of this thesis - Carland essentially worked as a curator of 1980s and 1990s culture, displaying her collection of artifacts within the pages of her zine. Carland collected clippings, images, and other ephemera from mainstream sources and then carefully arranged her findings alongside original writing and imagery to fabricate a tangible version of her unique perspective. Every element of $I \boldsymbol{\bullet}$ Amy Carter serves as an index that points to the ways in which she read the world around her; every pasted bit of material represents a different facet of her personality. As a whole, $I \boldsymbol{\vee}$ Amy Carter is the visual representation of Carland's continual process of identity-construction. The imagery and text on each page work symbiotically to express her politics, her ideologies, and her philosophies on life as well as her queer, feminist, welfare-class identity.

By sharing her thoughts and experiences in this zine, Carland also generates a counterpublic sphere - an alternative, dialectical public realm whose participants have been marginalized by dominant culture — where others with similar beliefs and 
circumstances are safe to do the same. These public acts of intimacy - the verbal, visual, and textual manifestations of stories of alienation divulged within the bounds of a counterpublic sphere - are significant, as they enable the physical manifestation of alternative testimonies. These acts effectively make visible the consequences normative ideologies enact on transgressive bodies.

On the surface, I Amy Carter appears to be a fanzine dedicated to its namesake. However, much of its content engages with serious social issues. The giant leap from celebrity devotional to cultural intervention begins with the zine's title and is carried forward by a concept Carland calls "Amyness." The heart in the title I Amy Carter reflects Riot Grrrl's re-appropriation of the aesthetic of girlhood but it also points to a common expression of youthful love and desire. The phrase "I [insert name here]" has been scrawled across binders, in diaries, and on the hands of teenage girls for years. It is a cute, silly, naïve articulation of an emotion that is almost always unrequited, especially when concerning the realm of celebrity fandom, which is almost exclusively the domain of adolescent girls.

Initiated by popular culture through various modes of media such as music and the movies, the unattainable celebrity crushes of teenage girls have been perpetuated for decades through magazines such as Tiger Beat and Seventeen. Carland chose the title "I $\checkmark$ Amy Carter" fully aware that it is rooted in this established tradition. It is emblazoned in oversized text on the candy-colored cover of every issue along with a photograph of Amy Carter and other girly adornments such as clip-art stars. These elements indicate the root of Carland's reverence of Carter, echoing a childlike sentiment, but read more 
closely they also begin to hint at the true subject matter of $I \vee$ Amy Carter, including aspects of Carland's identity such as her queer sexuality.

In every issue Carland acknowledges her crush on Carter by sharing photographs, doodles, stories, and news articles about her. However, it is clear that she is drawn to her for reasons other than physical attraction, especially when she details the concept of Amyness, which Carter inspires directly. Carland believes that childhood obsessionswith people, places, objects, and so on-translate into mental spaces that children create to keep themselves safe from the sadness and danger of the outside world. Her obsession with Amy Carter's celebrity_Carter's “safe” upbringing in the White House presumptively free from the dangers of poverty and abuse, her political activism as a young woman, and her socially conscious art making_represents Carland's own escape from the physical and emotional turmoil she endured as a child and a young adult.

Carter's intellectualism also inspires Carland to reach for greater opportunities in her own life. She writes:

Amy is an idea, a concept, a token of geek love, a hero, and more specifically she is safe and unknown...Amy is a leftover from my childhood, she is the residue of the elaborate fantasy life I lived as a child. She is who I wanted to be, or wanted to love, or wanted to know - depending on any given day. She is also a reminder of my first crush and/or heroizing of another girl. AMYNESS is about prioritizing girls and women and not feeling like you need to explain why to anyone and not worrying about alienating boys and men. AMYNESS is also about paying close attention to the girls and women who get accused of being 'smarty pants' - 'to smart for their own good' - 'big mouths' - 'too serious' - and my all time favorite, 'femi-nazi dyke'. I adore all of these qualities in a woman...if for some reason this ever finds its way to you Amy, I hope that you realize it all has a lot more to do with me than with you. ${ }^{1}$ (Carland Summer 1993: 3)

\footnotetext{
${ }^{1}$ Beginning here, I will not edit excerpts I have taken from the writing of Tammy Rae Carland or other Riot Grrrls unless edits are necessary to comprehension. The typos, misspelled words, grammatical errors, and other quirks in Grrrl zines and Grrrl writing are an important aspect of
} 
Amyness is a combination of the innocence, silliness, and gravity of real life. It is about encouraging young women to not be fearful of raising their voices and to be proud of their intelligence. The content of $I \vee$ Amy Carter follows this pattern. As this thesis will show, Carland's zine is both loud and smart while not being afraid to expose that it is simultaneously funny and unrefined; deadly serious and emotionally raw; full of shame and exploding with pride; beautiful and unapologetically messy.

Amyness galvanizes Carland and encourages her to become her best possible self by exploring, illuminating, and learning from the experiences in her own life as well as the social issues that plagued contemporary American society. The key issues addressed in $I \vee$ Amy Carter involve gender, sexuality, class, and race - subjects that were and continue to be of significant concern to intersectional feminists beginning in the early 1980s. The subjects with which Carland is most intimately familiar-gender, sexuality, and class - are discussed more comprehensively than race, but she tries to find ways to emphasize her belief that all are equally significant.

As a Riot Grrrl and zine creator, Carland was an active contributor to Riot Grrrl's environment of girl love. ${ }^{2}$ This environment required Riot Grrrls to participate in reciprocal acts of personal disclosure in order to foster a supportive and tightly-knit community as well as to effectuate collective, subversive political acts. This insistence engendered a world of public intimacy that carried with it a number of benefits and

their do-it-yourself, anti-mainstream attitude - a perspective that accepts and even embraces flaws and imperfections.

${ }^{2}$ Carland reiterates this position in the tagline she pastes on the back cover of each issue of $I$ Amy Carter, discussed further below. 
challenges. ${ }^{3}$ For many young women, Riot Grrrl provided a place where they felt safe to be themselves, free from the alienation of mainstream culture. However, a number of young women of color felt marginalized by Riot Grrrl's emphasis on intimacy as it demanded too much of them with too little reciprocity.

Both the positive and negative consequences of public intimacy are apparent throughout $I \vee$ Amy Carter. Carland repeatedly emphasizes the complexity of intersectional identities but sometimes she struggles to represent their different facets. She does, however, encourage her readers to be self-reflexive and she urges them to be supportive of underrepresented communities. Throughout $I \vee$ Amy Carter, she also makes it clear that she believes continual education (formal and informal) is the key to overcoming oppression. For Carland, knowledge truly equals power so she proposes her readers perform their own analyses to gain insight into their lives and environments. She is especially adamant that they continue to probe the infrastructure of institutionalized discrimination.

\section{The Shift from Essentialist to Intersectional Feminism}

Carland's struggle to implement intersectionality into her zine and daily life is indicative of the significant shift in feminist consciousness between the 1970s and early 1990s. In the early 1980s, a number of feminists began to question the aims of the second-wave arguing that its ideologies were essentialist—-based in the interests of white, middle-class women, and problematically invested in the idea of universal sisterhood-

\footnotetext{
${ }^{3}$ Riot Grrrl's world of public intimacy is analogous to the counterpublic sphere and public acts of intimacy discussed above. It was an alternative, dialectical public realm created by a group of alienated people (Riot Grrrls) that manufactured verbal, visual, and textual ephemera (music, an aesthetic, zines) that recognized their interests (feminism, popular culture, politics) by means of divulging some of the personal details (experiences, interests, points of view) of one's life.
} 
and, as a result, ultimately negated the complexities of the lived realities of countless women. Jill Fields categorizes this new mode of feminist thought as "anti-essentialist," explaining its position as "focused on the distinction between sex and gender, finding the latter a socially constructed, historically situated phenomenon" (2012: 5). Antiessentialists criticized the women of the second-wave for prizing an "ahistorical female biological 'essence' that mirrored and therefore sustained anti-feminist ideologies and inequitable gender structures," an assertion that many feminists, including Mira Schor, have since argued is not entirely accurate (Fields 2012: 5). Schor contends that although the second-wave's approach to feminism was not entirely without fault, its philosophy was (necessarily) born out of opposition to its contemporary oppressive circumstances (Fields 2012: 5). Regardless of opinions on the intentions of the second-wave, the disjuncture that occurred in response to differing interests resulted in significant changes within the larger feminist community.

In addition to anti-essentialism, Fields also points to poststructuralism as influential to the revision of feminist philosophy at this time, setting it up as a key factor in the formation of intersectionality. She writes:

[In the 1980s, ] poststructuralism directed attention to the operations of language and mobilization of discursive strategies and thus provided theoretical frameworks for intensified questioning of gendered categories and their constructions and for explaining why oppositional movements had faltered. Yet in directing attention away from fixed centers of power and authorial/artistic attention, some strains of poststructuralism undermined or set aside as passé the work undertaken by women and people of color to represent their subjective experiences, imagine social and cultural transformations, create alternative institutions, and articulate standpoints against inequitable and what often appeared to be immovable hierarchies. (Fields 2012: 5) 
As Fields indicates, poststructuralism opened up new venues of thought concerning the boundaries of gender, but it still minimized the expression of oppressive experiences. Toward the end of the 1980 s, feminists began to recognize that some aspects of essentialist feminism were necessary to fully comprehending the nature of gendered difference because, as Diana Fuss pointed out, “the categories of 'man' and 'woman' remain constant" regardless of the fact that they are socially constructed (Fuss quoted in Fields 2012: 6).

In 1989, building upon the earlier analyses of feminists of color, Kimberlé Crenshaw introduced the notion of intersectional feminism. Intersectionality combines aspects from all of its feminist forbearers. It allows room for the expression of personal experiences, but it also examines the "multiple and overlapping constructions of gender, race, class, and sexuality" (Fields 2012:8). Intersectionality broadened feminist discourse, and, as Fields notes, carried over into a variety of other disciplines including "the concept of borderlands articulated by Gloria Anzaldúa and Chicana feminists, the closet and queer perspectives from gay and lesbian studies...the rethinking of the body offered by feminists working in disability studies" as well as concepts of diaspora and the transnational (2012: 8). The complexity of intersectional feminism can be overwhelming but it is also significant because it necessarily requires and perpetuates varying degrees of social and self-consciousness. Intersectionality is not just interested in the experiences of one group of oppressed women, it is interested in the stories of all women, and really all people. Scholars who look to this analytical tool are especially intent upon examining where the different aspects of identity—race, class, sexual preference, etc.—cross paths. 
As part of a new generation of feminists, Carland and Riot Grrrls were eager to make their own mark on the movement, and the expansive concept of intersectionality provided them with the ideal foundation on which to base their own socio-cultural critiques. In the 1980s and early 1990s, when Carland was growing into adulthood and Riot Grrrl was in its nascent stages, the idea of intersectional feminism was also just beginning to develop. Based on this knowledge, it is easier to understand how and why Carland and Riot Grrrl struggled to implement intersectionality in their feminist practices. Although both have been rebuked for their difficulty in addressing issues such as race and/or class, their endeavors remain a significant component of the third-wave and the broader history of feminist discourse, and, as evidenced through the outlets Riot Grrrls employ such as music and zines, intersectionality is still an integral part of their critical reflections.

"SOME HELPFUL HINTS FOR A LITTLE R + R (RAGE + RESISTANCE)"

$I \vee$ Amy Carter \#2 features a two-page spread that embodies the visual and philosophical essence of the zine. The layout of these pages is typical for Carland; she combines imagery and text that not only speak to each other's meaning, but also accentuate the zine's overall cut-and-paste aesthetic. The first page includes a decorative header of clip-art stars, plus signs, and an arrow followed by the first part of an essay written by Carland. The second page includes the final part of Carland's essay with two separately pasted phrases and a large photograph of Amy Carter. The essay, titled “SOME HELPFUL HINTS FOR A LITTLE R + R (RAGE + RESISTANCE),” lists eleven ways for Carland's readers to be productive and proactive members of society while simultaneously refusing to settle for the normative social constructs that dictate the 
boundaries of gender, sexuality, class, and race. She writes:

1. Trust your instincts, they are perhaps the one constant source of protection and defence that women have available to them.

2. Be politically active, and this doesn't mean just voting. There is POWER and KNOWLEDGE in numbers. So don't get overwhelmed, focus on one thing if you have to and join an organization or at least affiliate yourself with one. Despite what people may say this has always been the most affective way to take action.

3. Start an organization, or a band, or a fanzine, or a business, or co-op living situations, or create a venue for networking. These options are unlimited so be creative, the basic premise being both independence and control over choosing who you are inter-dependent with. All of the important people in my life have come from these kinds of projects.

4. A self defence course is an incredibly empowering action to take. Learn how to do body flips and ball busting kicks, it's such a high.

5. Face reality. The fact of the matter is that we (you and I) are more likely to be severely injured (physically +/or emotionally) by someone that we know and maybe even love than by a stranger. Although queer + woman bashing incidents are on the rise and the 'stranger lurking in the bushes' is far from a myth.

6. Name yourself, Identify yourself, don't let others do this for you. Take back what you want for your own. If you own it others will be hard pressed to use it against you. So be a Feminist - Dyke -Trash - Slut - Good ol' Fashioned Tuna Sandwich if you wanna be.

7. OFF THE PIGS.

8. Look beyond yourself. Unfortunately (I think) we are not islands. Never get stuck in the position of prioritizing the elimination of your own oppression without considering (and taking action) in regards to how you fit in to the evolutional chain of privilege and power. In other words race, class, gender, sexual orientation and practices are not mutually exclusive identities and ideologies - they are extremely dependent on one another. Start by recognizing what you do and don't have access to according to who you are and who you are not.

9. Support businesses that are owned and operated by women, queers and people of color. Let's face it we are all consumers, to varying degrees, so this is perhaps the most effective daily practice we can commit to.

10. Educate yourself as much as possible and don't ever stop. If you don't chose college support those who do. I'm so sick of dogmatic statements like 'higher education is a conservative and elitist choice' or 'art is a capitalist tool'. DUH! It doesn't take much critical thinking to find the holes in that bullshit. Education doesn't (and shouldn't) just happen in institutions. So support one another's decisions and openly share information and ideas. 
11. Know your body. Have as much knowledge and control as you possibly can over your own body and health. Practice preventive maintenance, safe sex, and by all means allow yourself pleasure. (Carland March 1993: 23-24)

These "HELPFUL HINTS" point to Carland's interpretation of girl love, which emphasizes self-empowerment and underscores the importance of supportive communities, self-reflexivity, and continual education. Ultimately, Carland suggests that young women have the power within them to take control of their bodies and environment and also to enact change if only they put forth the effort and remain diligent in their endeavors.

Carland's suggestions make it clear that she does not believe in reticence or complacency. Her convictions are further expressed in combination with the accompanying image of Carter along with the pasted phrases, which physically and metaphorically punctuate her enumeration. The photograph depicts a young, grinning Amy Carter, a few of her friends, and Carter's "famous lemonade stand." At the beginning of this same issue, Carland shares two lighthearted newspaper clippings that detail Carter's foray into lemonade entrepreneurship. During her father's presidential campaign, Carter established her own lemonade stand where she and her friends sold lemonade to reporters "at outrageous prices"- ten cents per cup (Carland March 1993: 5). ${ }^{4}$ Pasted to the left of the image in emphatic text is, "FACE IT GIRLS ARE THE COOLEST." Carter's independent, take-charge, sassy spirit, as demonstrated through her lemonade business, echoes Carland's emphasis on self-empowerment. This photograph,

\footnotetext{
${ }^{4}$ The story of Amy Carter's lemonade stand was a favorite of reporters; it was written about repeatedly. "Amy's Lemonade" even warranted its own special recipe. After Jimmy Carter was elected president, it was featured in a variety of periodicals. Carland shares one of these recipes clipped from an unidentified source in I $\bullet$ Amy Carter \#4 (January 1994: 15).
} 
situated alongside her "HELPFUL HINTS," essentially serves as a motivational example. Carter saw an opportunity and ran with it—Carland's readers can do the same.

Between the last of Carland's "HELPFUL HINTS" and the photograph of Carter at her lemonade stand is a phrase in large, capitalized text accentuated by a black frame that reads, "WHO IS IT THAT TOLD ME THAT RAGE WAS TO SWALLOW AND CHOKE ON YOUR TONGUE" (Carland March 1993: 24). These words reflect once again Carland's opposition to silence and passivity. Young women were not supposed to harbor rage let alone manifest it, but Carland and other Riot Grrrls were filled with it. Rather than repress their rage and keep it invisible, Riot Grrrls loudly expressed it in creative ways employing it as a weapon to destabilize the footing of oppressive frameworks. I Amy Carter contributed to Riot Grrrl's fight, adding Tammy Rae Carland's perspective to the movement's developing identity.

\section{Riot Grrrl's Enduring Legacy}

Riot Grrrl occupies a significant place in feminist history and the cultural history of the United States. It was a revolutionary movement for innumerable young feminists during the 1980s and 1990s, and in less than a decade it fabricated a lasting and distinct identity by maintaining a dynamic presence through material ephemera such as music and zines. Riot Grrrl zines occupy a unique locale in material culture - they are too complex to be considered the mere byproducts of a social movement, yet they are not quite befitting of fine art's definition of suitable works for analysis. The ways in which Grrrls pulled material from preexisting culture and entwined their selections with their own writing and imagery is a meaningful act that is best approached from the interdisciplinary field of visual culture. 
Visual culture dissolves hierarchies and combines useful components from a number of academic fields in order to foster critical thinking and make sense of the myriad of image-based experiences and materials the world has to offer. Visual culture's flexibility allows me to analyze $I \bullet$ Amy Carter as the tangible expression of Carland's politics and identity. It also provides a framework for Riot Grrrl's world of public intimacy. In the last ten years, Riot Grrrl has seen a major resurgence. It is inspiring a new generation of young women who express Grrrl sentiments in new venues, such as blogs and other online forums, and who also continue the Riot Grrrl zine tradition. The movement has also piqued interest in the academic community, triggering investigations by various disciplines including sociology, literature, and women's and gender studies.

In 2007, Nadine Monem edited the book Riot Grrrl: Revolution Girl Style Now! which discusses the influences of Riot Grrrl, the movement's peak, as well as its effect on modern day feminist Punk musicians. In 2009, senior archivist Lisa Darms founded the Riot Grrrl Collection at the Fales Library and Special Collections at New York University. The Collection attracted so much interest that in 2013 Darms published a book titled The Riot Grrrl Collection which features a variety of the printed material stored in the archives including zines, flyers, and correspondence. In 2009, Alison Piepmeier published Girl Zines: Making Media, Doing Feminism. This study demonstrates how girl zines, including those created by Riot Grrrls, enact feminism and operate in the cracks of society as micropolitical pedagogies. In 2010, Sara Marcus published one of the most popular texts on Riot Grrrl, Girls to the Front: The True Story of the Riot Grrrl Revolution. Marcus' book provides an in-depth look inside the 
movement through a comprehensive history that details the good, the bad, and the positively ugly moments of its existence.

The scope of much of the writing on Riot Grrrl—including many of the texts listed above — is broad and tends to provide historical accounts of the movement rather than more focused and analytical studies. Recently, Mimi Thi Nguyen—a disillusioned Riot Grrrl contemporary turned academic — wrote an article that hones in on an aspect of Riot Grrrl culture that many other narratives generally gloss over. The article is titled "Riot Grrrl, Race, and Revival" (2012) and it critiques Riot Grrrl's encounters with race, detailing some of the negative ramifications of the movement's insistence upon an environment of girl love, or what Nguyen calls "a world of public intimacy." Nguyen's critique is illuminating and distinct from other accounts of Riot Grrrl that tend to obfuscate messier details in favor of the movement's revolutionary aspects. However, her analysis does not address the ways in which public intimacy can be beneficial to those who choose to employ it. Queer theorist Ann Cvetkovich engages with this possibility in her book An Archive of Feelings: Trauma, Sexuality, and Lesbian Public Cultures (2006). Cvetkovich argues that by engaging in acts of public intimacy—more specifically, by elucidating the psychic affects of trauma - a dialectical environment is generated that is beneficial to its disaffected participants because their experiences are physically manifested rather than "erased" and made invisible as they are through interventions that are strictly medical.

This thesis pulls from the lineage, history, and contemporary cultural conditions of Riot Grrrl to analyze Tammy Rae Carland's queer Grrrl zine I Amy Carter as a counterpublic sphere — an alternative, dialectical realm for the alienated — that is 
engendered by acts of public intimacy — the verbal, visual, and textual manifestations of the experiences of the alienated - that make visible the intersectional complexities of gender, sexuality, class, and race that insidious traumas continually work to conceal. I employ Cvetkovich and Nguyen's analyses of public intimacy as a means to perform my own critique of the ways in which Carland interacts with Riot Grrrl's world of public intimacy in the pages of her zine. I analyze the relationship between Carland's visual and textual articulations of intersectionality and the ramifications of misogyny, homophobia, classism, and racism, revealing the parallels and fissures between what she says and what she shows. I argue that Carland's participation in this world is distinct from the involvement of many other Riot Grrrls and that $I$ Amy Carter corroborates Cvetkovich's position that creative public discourse that elucidates the consequences of insidious traumas can produce positive effects.

\section{Thesis Overview}

Carland is not simply the author of $I$ Amy Carter; she also acts as a curator and an archivist of visual, verbal, and textual culture within its pages. Consequentially, $I$ Amy Carter is read through her subjective lens and functions as the expression of her politics, ideologies, and philosophies. The selective eye Carland employs when constructing $I \vee$ Amy Carter embodies the expected flaws of such a process, however, it also enriches the zine. As a lesbian and former welfare-recipient, Carland has endured a more difficult life than many people. The distressing experiences elicited by her aberrant identity make her more aware of some of the harsher ways the world functions, especially where social alienation is concerned. As such, many of the stories shared in $I \vee A m y$ Carter provide tangible, alternative testimonies about life during its creation. This thesis, 
then, is simultaneously a reading of a reading, an examination of the relationship between Carland's textual expressions and what she presents visually, and a critique of her contemporary culture.

I begin Chapter II by describing why Riot Grrrls felt compelled to enact a public environment of girl love, what participation in this environment required, and what types of changes girl love was supposed to effectuate. I then describe Cvetkovich's investigation into the positive aspects of public intimacy. I explain how Cvetkovich expands the definition of trauma to include psychic affects and how this new approach ultimately engenders the counterpublic spheres that make the experiences of the disaffected tangible and keep these histories visible. I also introduce the notion of insidious trauma and begin to describe how its various frameworks operate in mainstream society. In this chapter, I also detail Nguyen's analysis of girl love—or Riot Grrrl's world of public intimacy — and her contention that Riot Grrrl's insistence on this environment was more intrusive than resistant for Grrrls of color. I elaborate upon Nguyen's argument that the Riot Grrrl race crisis was rooted in their inability to look outside of themselves to the structural determinations of race and begin to hint at Carland's relationship to this race crisis in the pages of $I \vee$ Amy Carter.

Chapter III, parts I and II contextualize I Amy Carter in mainstream history and Carland's personal life to help situate the instances of public intimacy that it demonstrates. In chapter III, part I, I trace the lineage of Riot Grrrl culture from the 1970s Punk scene and second-wave feminism through the emergence of Hardcore Punk and the third-wave in the 1980s and early 1990s. I also address some of the major contemporary civil issues that afflicted American society during the 1980s and 1990s, 
including the ramifications of its neo-conservative environment as well as the implications of the widely disseminated notion during the Reagan era that the United States had entered a state of "post" feminism.

In chapter III, part II, I recapitulate some of the significant events that Carland details about her life, including her severely impoverished upbringing in Portland, Maine, the influence Riot Grrrl had on her while attending Evergreen State College in Olympia, Washington, and the trajectory of her career after graduating and leaving Olympia. I address an essay Carland wrote in graduate school titled "Allowing a Little Class to Leak Out (the puddle under the table)" (1993) in which she expresses some of the effects that being a member of the welfare-class has had on her life and identity. I also discuss some of Carland's intentions behind the creation of I Amy Carter, reflecting upon the ways in which the zine is representative of Carland's identity. Finally, I begin to elaborate upon $I \vee$ Amy Carter as a counterpublic sphere.

In chapter IV, I explore the tension between Cvetkovich and Nguyen's analyses. I employ both authors' viewpoints as a means to investigate the acts of public intimacy carried out in I Amy Carter that transform it from fanzine to counterpublic sphere. I discuss the policing of transgressive identities by dominant culture, critiquing the ways in which Carland visually and textually articulates the consequences of these insidious practices, citing specific pages and elements from the zine as example. The structure of this chapter follows the pattern in which Carland addresses gender, sexuality, class, and race. Sometimes discussions of these subjects overlap, but they are more often discussed individually. 
Chapter IV, part I, examines Carland's interactions with gender and sexuality. I begin by explaining how Riot Grrrl responded to the mainstream's conflation of these two categories by simultaneously embracing and countering feminine gender roles with an overly cute but acidic aesthetic and attitude. I discuss the ways in which I Amy Carter visually and textually reflects Riot Grrrl's expression of gender and sexuality and the ways in which these elements make visible the harmful consequences of misogynist and homophobic practices. I examine how Carland reclaims authority over gendered, sexualized, and queered bodies by embracing dominant culture's attempts to shame transgressors with the distorted and derogatory notions it perpetuates through language and representation. I also discuss how Carland further combats shame by presenting her readers with imagery and writing that promotes sex-positivity, sexual-diversity, and sexual-education.

In chapter IV, part II, I begin to examine the disconnect between Carland's affirmation of intersectionality and her struggles to implement it in her zine. I revisit Nguyen's analysis of the Riot Grrrl race crisis and use her observations as a gauge to explore Carland's interactions with race, again, citing specific examples from $I \checkmark A m y$ Carter to build my critique. Carland's articulations on this subject are limited and when she does approach race, she does not personally address the subject; instead, she relies upon appropriated statistics, writing, and imagery to express her viewpoint. I survey this methodology and discuss how it straddles the border between successfully addressing the institutionalization of racism and, contrarily, ossifying its oppressive frameworks.

In chapter IV, part III, I expand upon the disjuncture between Carland's words and imagery with a subject she is particularly adept at expressing through writing —class. 
This section is grounded in an essay Carland wrote, titled "REFLECTIONS OF A STUPID SLUT \{or, a frigid feminist - depending on how you look at it\}," in which she recounts her experiences as welfare-dependent child. I discuss how this narrative forefronts the lived reality of welfare-recipients, complicating the oversimplified notions of the welfare-class that are perpetuated by dominant culture. I also address the lingering desire for visibility that Carland expresses in this essay. I draw upon the few instances where she visually articulates this longing as examples of how the experiences of the underprivileged might be justly represented without simply operating in strict opposition to mainstream portrayals.

This thesis situates $I \bullet$ Amy Carter historically and culturally to contextualize and illuminate its politically-charged content. Cvetkovich and Nguyen's analyses of acts of public intimacy provide a framework upon which to critique $I \boldsymbol{\vee}$ Amy Carter as an extension of Riot Grrrl's world of public intimacy and also as a counterpublic sphere. I argue that Carland's expressions of girl love are unique and generative, but her articulations of intersectionality and her personal philosophies and politics were still, at the time when she created her zine, developing. Ultimately, Carland's visual and textual representations of the lived realities of transgressive bodies in I $\boldsymbol{\vee}$ Amy Carter demonstrate how Cvetkovich and Nguyen's understandings of public intimacy can be united to reveal the ways in which insidious traumas initiate and then perpetuate their oppressive frameworks. 


\section{CHAPTER II}

\section{ON GIRL LOVE AND PUBLIC INTIMACY}

When Riot Grrrl caught the attention of the mainstream media in the early 1990s, it was largely showcased as a group of outspoken, self-absorbed teenaged and collegeaged girls who received an impulsive feminist agenda from girl-fronted Punk bands and the movement's purported commander-in-chief, Kathleen Hanna. Although contemporary coverage of Riot Grrrl was troubling in many ways, it was also telling as it reveals a great disparity within a movement that was hell-bent on girl love. A disproportionate number of Grrrls featured in mainstream publications were white, but this was not simply another instance of institutionalized racism in mainstream media. The fact is that Riot Grrrl was a predominantly white movement. In the midst of the third-wave, when feminist thought was shifting to include intersectional nuances such as class and race-status, Riot Grrrl still found itself trapped both in whiteness and middleclass conceptions of life experience. In the mid- to late 1990s, despite its continual denouncement of racism and promotion of diversity in Grrrl zines, lyrics, and political activities, Riot Grrrl ultimately succumbed to its inability to successfully integrate intersectionality. Grrrls were blinded by their eagerness to eradicate their personal 
affiliations with racism and could not see into the heart of the issue. They did not think to consider how racism (or class) had come to be embedded into society. ${ }^{5}$

This chapter recounts Cvetkovich and Nguyen's arguments about acts of public intimacy. I begin by detailing the concept of girl love and its relationship to intersectionality. I then engage with the positive possibilities of public intimacy as delineated by Cvetkovich. I elaborate on her conception of trauma as an affective condition as opposed to a medical symptom, and how this shift in perception illuminates the ways in which the articulation of personal traumatic experiences can engender positive dialectical counterpublic spheres. I recapitulate Cvetkovich's conception of insidious trauma, characterizing the forms in which it is present in $I \boldsymbol{\vee}$ Amy Carter.

This chapter also engages with Nguyen's conception of the Riot Grrrl race crisis, explaining how Grrrls' insistence on a world of public intimacy ultimately alienated Grrrls of color. I explain Nguyen's contention that white Grrrls were misguided in their attempts to employ proximity as a means to eradicate racism and how this concept ultimately ossified preexisting oppressive systems. I conclude this chapter by setting up $I$ $\checkmark$ Amy Carter as the type of counterpublic sphere Cvetkovich visualizes, which engages with insidious traumas visually and textually, ultimately challenging Nguyen's negative notion of public of intimacy.

\section{Riot Grrrl's World of Public Intimacy}

Although small in number, Riot Grrrls of color existed and participated fully in Grrrl culture. They contributed to and created their own zines, were members of bands,

\footnotetext{
${ }^{5}$ My discussion in this thesis is not centered on race. I will, however, refer often to the significance of white Riot Grrrls' relationships to racialization-which were tenuous and confused at best - as a means to demonstrate Carland's departure from some of the underdeveloped tenets of Riot Grrrl culture.
} 
attended meetings, and walked alongside white Grrrls at political protests. But as the movement progressed, more and more Grrrls of color deserted while many young feminist Punks of color avoided it entirely. Riot Grrrl could not fulfill their need to be recognized without being burdened to educate an entire movement about what life was like as a non-white racialized "other." Riot Grrrls believed that mainstream culture was pitting girls against one another as a means to reinforce normative, submissive feminine roles. In order to thwart these tactics, Grrrls insisted upon an environment of girl loveNguyen's “world of public intimacy"-in which sharing personal stories not only fostered friendships but also came to serve as forms of knowledge that were intended to minimize differences and eradicate not just racism but all forms of discrimination.

Although Riot Grrrl's intentions were noble, its tactics were not sufficient to make young Punks of color feel their efforts were reciprocated or that their circumstances were truly understood.

Tammy Rae Carland, like her Riot Grrrl counterparts, also aimed to recognize the intersectionality of identity through I Amy Carter. Because she too had experienced unwarranted acts of discrimination due to her gender, sexuality, and social class, Carland attempted to be as inclusive and as receptive as possible in her zine. Although a proportionate amount of feminist discussion in I $\boldsymbol{\vee}$ Amy Carter revolves around sexuality, gender, and class, race is still a key issue. Carland may not discuss it as intensively as the subjects that constitute her own identity, but she does explore race. Unbridled by the strict guidelines of mainstream periodicals, every Grrrl zine contributed its own unique aspects to the continual construction of Riot Grrrl's identity. Some of these contributions benefitted the community while others created divisions. But even the ugliest of 
situations - for example when white Grrrl Erika Reinstein invoked the "one-drop" rule to support her claim that she was an African American woman-ultimately challenged Grrrls to be self-critical (Nguyen 2012: 183).

Girl love is the essence of Riot Grrrl identity - every facet of the community is the result of Riot Grrrl's insistence upon this world of public intimacy. In An Archive of Feelings: Trauma, Sexuality, and Lesbian Public Cultures (2006), Cvetkovich examines how public intimacy can be a beneficial act, arguing that it provides participants with the means to create their own communities where their stories will not be overlooked or erased. Conversely, in the article "Riot Grrrl, Race, and Revival” (2012), Nguyen explores the adverse effects of Riot Grrrl's insistence on public intimacy, citing what she considers the movement's forced participatory environment as its downfall. Both of these interpretations prove useful in analyzing the efficacy of the Riot Grrrl movement, providing insight into the ways in which Carland engaged with this candid environment in $I \bullet$ Amy Carter.

\section{Ann Cvetkovich Explores the Positive Possibilities of Public Intimacy}

Ann Cvetkovich's exploration of the potential benefits of public intimacy for survivors of various forms of trauma in her book An Archive of Feelings: Trauma, Sexuality, and Lesbian Public Cultures (2006) offers a solid premise upon which to analyze the positive consequences of Riot Grrrl's own world of public intimacy. Cvetkovich cites her experience of the band Le Tigre's live performance of the song "Keep on Livin"” as one of the paramount examples of addressing trauma without treating it like a terrorizing aberration. She writes: 
[Kathleen] Hanna's cry of 'you gotta keep on' sounds like an impossible demand for survival, but when the chorus answers with 'keep on, keep on livin',' it sounds like the cheer that can help sustain you. Performed live, the song creates an opportunity for the audience to shout out the words as a group and affirm the many kinds of survival that bring them together. The music helps return the listener to the pleasures of sensory embodiment that trauma destroys: 'Cuz those are your arms, that is your heart and no no they can't tear you apart'...The combined power of song, visuals, and live performance lends itself to the formation of a public culture around trauma that doesn't involve medical diagnoses or victims. (Cvetkovich 2006: 1)

Cvetkovich believes that publicly acknowledging trauma through cathartic processes is in many ways more restorative than bandaging the wounds that it creates which she believes can never fully heal.

\section{Trauma Beyond Clinical Terms}

Cvetkovich complicates the mainstream consensus that trauma is strictly a medical problem by arguing that traumatic events are rooted in social issues. She asserts that many of trauma's consequences, as well as the manner in which those consequences are handled, are the result of human invention. She argues that many of the behaviors that do not adhere to the conventions of dominant society are pathologized in order to perpetuate normative standards. Homosexuality, for example, was labeled a disease in the nineteenth century as a means to bolster heteronormative sexual identities and punish sexual deviants (Cvetkovich 2006: 44-46).

Cvetkovich is in no way denying the real effects of trauma or attempting to completely discount its clinical treatment. Rather, she is pointing to the aspects of trauma that are obfuscated by such delineations. Just as the medicalization of homosexuality demonstrates, clinical definitions of trauma approach it in the same manner as any other medical condition. The symptoms are analyzed, a prognosis is given, and treatment is 
administered with the goal that the condition subsides or is eradicated completely. In this scenario, trauma manifests as a physical malady that can and must be resolved in time (Cvetkovich 2006: 44). This is a problematic notion for Cvetkovich because in addition to physical symptoms, trauma also produces psychic affects - a type of symptom that can never truly be erased. Ultimately, the insistence upon rectifying trauma only renders it invisible.

Cvetkovich suggests an alternative interpretation of trauma in which it is conceived of as "a social and cultural discourse that emerges in response to the demands of grappling with the psychic consequences of historical events" (2006: 18). This interpretation emphasizes that the consequences of traumatic events are not simply physical, they are also psychic. Because trauma has been persistently made invisible by its medicalization, Cvetkovich proposes that it "demands quite a different approach, one that can recognize trauma's specificities and variations" (2006: 3 ). She notes that the psychic affects of trauma can often be difficult and sometimes even impossible to represent for two reasons; because these affects are not necessarily tangible and because many people are programmed to push trauma to the recesses of their minds. Trauma's peculiar nature is precisely why, Cvetkovich argues, it "demands an unusual archive, whose materials, in pointing to trauma's ephemerality, are themselves frequently ephemeral" (2006: 7).

Trauma lingers because it feeds on personal memories, which are also oftentimes immaterial. Cvetkovich suggests that publicly engaging with trauma through processes such as spoken or written testimony—-through video recordings, performances, letters, memoirs, and so on—can give intangible memories substance. Once physically 
manifested, trauma is capable of generating counterpublic spheres in which its affects can be archived rather than lost or presumptively destroyed. ${ }^{6}$ These counterpublic spheres not only help survivors cope with the enduring consequences of traumatic events, they also keep trauma and its repercussions visible (Cvetkovich 2006: 8 and 15).

I Amy Carter is an example of one of these counterpublic spheres in action. The public acts of intimacy Carland fosters in this zine allow her and her contributors to articulate their experiences without being forced to overcome their histories. Instead, by sharing these stories in a space that others with similar experiences can access and even contribute to, a dialectical environment is generated in which it is safe to make oneself vulnerable and interact with wounds that are systematically rendered invisible.

\section{Insidious Traumas}

Not all of the events and psychic affects discussed in I Amy Carter are traumatic in the primary sense. A few accounts verbalize the physical and psychic ramifications of harrowing experiences such as incestuous rape, but many more detail feelings of social alienation and the lived repercussions of widespread discriminatory practices. Cvetkovich, however, creates room for the affects elicited by systemic oppression such as sexism, homophobia, classism, and racism, by placing them in the category of insidious trauma. As the name implies, insidious trauma "is effective precisely because it leaves no sign of a problem" (Cvetkovich 2006: 46). Cvetkovich specifically cites "the normalization of sex and gender identities" as forms of insidious

\footnotetext{
${ }^{6}$ Cvetkovich likens counterpublic spheres to grassroots efforts. In her definition, counterpublic spheres are created by people who have been neglected or rendered invisible by dominant culture. They operate outside of institutionalized frameworks and stand alongside official histories - in other words, dominant histories - to provide additional modes of knowledge (Cvetkovich 2006: $8)$.
} 
trauma; however, classism and racism can also be read as forms of insidious trauma because they too are normalized by the covert actions of dominant cultural apparatuses and they also generate similar psychic consequences (2006: 46).

Nguyen points to insidious racist practices as precisely the issue white Riot Grrrls overlooked when attempting to grasp the concept of racialization. She argues that their inattention to institutionalized racism (and, by extension, classism) resulted in a number of concerns. It placed undue burdens upon Riot Grrrls of color, forcing them to share their experiences and teach white Grrrls about what it is like to live as a non-white racialized "other." It also conferred upon white Grrrls a false sense of security concerning their relationship to racism, whiteness, and privilege.

\section{Mimi Thi Nguyen Critiques Riot Grrrl's World of Public Intimacy}

Mimi Thi Nguyen was sixteen years old in 1991 when she discovered Riot Grrrl. As a zinester and feminist Punk she was drawn to the movement but she never considered herself a member (Vasquez 2013: 40). Despite her detachment from Grrrl culture, Nguyen believes that Riot Grrrl was one of the most valuable outgrowths of the larger Punk scene, citing its creativity, intellectuality, and “critique of punk's masculinist aesthetics and politics" as some of its greatest assets (Vasquez 2013: 40). As a young woman of color and a student of women's and gender studies, she was also concurrently aware and increasingly critical of Riot Grrrl's racial issues. Now a professor of women's and gender studies and Asian American studies at the University of Illinois, UrbanaChampaign, Nguyen reflects upon this race crisis, drawing upon feminist theory and the movement's historiography to help articulate the relationship between Riot Grrrl and feminist Punk women of color. 
By cultivating a world of public intimacy, Riot Grrrl revived the second-wave feminist notion that "the personal is political," unwittingly setting itself up for many of the same issues that haunted its feminist predecessors. Refusing to be continually marginalized by normative doctrines - those dictated by white, middle-class, heteronormative males - the movement developed a position which decreed that personal experiences were viable alternatives for traditional forms of authentic knowledge (Nguyen 2012: 178-179). For Riot Grrrls, testimony was tantamount to reality and that reality contradicted dominant culture - they knew they were capable of accomplishing more than submissive feminine gender roles would allow. ${ }^{7}$ The sharing of stories ultimately revealed that mainstream truths and conventions functioned as façades for prescribed ideologies. Perpetuating their world of public intimacy meant not only building a supportive community, but also producing subversive political acts. Nguyen contends that the problem with this tactic was that it was not beneficial to all involved, especially when Grrrls attempted to engage with personal accounts of racism.

Nguyen connects Riot Grrrl's approach to oppressive frameworks to second-wave "consciousness-raising, and the notion that the deeply oppressed had radical knowledge stemming from their specific social positions" (2012: 179). She argues that this stance

\footnotetext{
${ }^{7}$ Here and elsewhere, I add the word "traditional" before "authentic knowledge" to delineate Nguyen's argument from Riot Grrrl's viewpoint on authenticity. To clarify, Nguyen contends that Riot Grrrls positioned testimony as a viable alternative for authentic forms knowledge. Riot Grrrls would have believed that the knowledge they accumulated from their personal experiences was not just an alternative but was, in and of itself, authentic because their encounters with gender, sexuality, etc. were not any less real even though these experiences did not align with what dominant culture projected. It is not difficult to understand Riot Grrrl's position for-as I will discuss in subsequent chapters - women continued to face oppression even after laws were enacted to protect their rights and despite mass media's insistence that feminism was obsolete. However, as I also discuss further below, testimony as knowledge does come with its own challenges.
} 
ultimately sets up an unbalanced relationship between Grrrls of color and their white counterparts, explaining that Riot Grrrl's insistence upon intimacy — the idea that every Grrrl shares her experiences as a means to "know herself and to be known by others"-is more intrusive than resistant for Grrrls of color (Nguyen 2012: 174 and 176; emphases original). As minorities within the movement and American culture, Grrrls of color were often "relegated to the [exhausting] role of educator" and in many cases were "labeled the enemy" when the stories they told evoked disturbing histories, or their critiques of dominant white culture made white Grrrls feel uncomfortable (Nguyen 2012: 180).

One of the reasons white Grrrls were distressed by some of these voices is because their self-reflexivity was called into check. White Grrrls believed their methodology effectively combated racism, but Grrrls of color argued that their practices only reified preexisting cultural conditions. White Grrrls relied too heavily upon their personal relationship to racism and on the first-hand accounts of oppression gleaned from Grrrls of color instead of questioning why racism existed in the first place. Nguyen contends that white Grrrls equated racism with ignorance and ignorance with a lack of intimacy "which suggests that proximity is a social prophylactic against virulent racism" (2012: 181). For example, when white Grrrls expressed shame or guilt about lack of engagement with people of color (or their desire for intimacy with them), Nguyen maintains they only did so as a means to prove that they were not racist (2012: 181-182). In other words, white Grrrls were more concerned with alleviating their own burdens than they were with truly confronting racism.

Common consensus is that Riot Grrrl ultimately disintegrated because Grrrls struggled with integrating race. When asked to reassess their relationship to racism, 
many white Grrrls shut down, becoming immediately defensive instead of receptive to the conversation (Marcus 2010: 165). Kathleen Hanna is frequently asked in interviews if there was anything about Riot Grrrl that she would have changed. Her response is always the same; she wishes white Grrrls had been open to productive dialogue about race instead of crying reverse racism when they were called out on their privilege. In Girls to the Front (2010), Sara Marcus corroborates Hanna's observation. She also describes how even after the movement began to fade in the mid-1990s, and a small group of Grrrls transferred their activities over to the Internet, problems addressing privilege still persisted (Marcus 2010: 326). Nguyen contends that the movement's fundamental problem was that too many Grrrls relied upon intimacy as a means to combat racism. By focusing their efforts inward and on their personal relationships with people of color instead of outward on the ways in which racism was embedded in culture, Grrrls worked within the predetermined and firmly situated boundaries of racism, effectively ossifying its existence (Nguyen 2012: 179). The ways Carland addresses race (and other forms of oppression) in $I \vee$ Amy Carter straddle the border between what Nguyen would view as complete failure and a more suitable plan of attack.

Carland neither incited white shame as proof of good intentions, nor did she ask Grrrls of color to educate her audience. Instead, she provided her readers with tools that illuminated not only institutionalized racism, but also institutionalized oppression of all forms. She also asked her readers to be conscious of the implications of their privilege, and encouraged them to critically engage with the mechanisms that create and perpetuate systems of domination. A number of Grrrls of color-including Ramdasha Bikceem in GUNK (1990-1994) and Ananda La Vita in White Girls, We Need to Talk (circa 1993) 
and Smile for Me (circa 1993) —examined institutionalized oppression in their zines, so Carland's efforts are not entirely unique. She also relies heavily on testimony in I Amy Carter and situates personal experience as an equally valid mode of knowledgemethods with which Nguyen takes serious issue in her analysis. However, Cvetkovich's investigation of public intimacy demonstrates how these acts can generate positive outcomes. Her viewpoint helps illuminate the ways Carland's endeavors are distinct from the problematic efforts Nguyen discusses.

$I \checkmark$ Amy Carter acts as the unusual archive Cvetkovich describes, where its testimonies of the affects of insidious trauma, now made tangible, come to serve as modes of knowledge whose authenticity Nguyen calls into question. However, there are nuances to knowledge that Nguyen does not recognize in her article. There is a difference between felt knowledge - truths based on personal experience — and intellectualized knowledge - truths that are created and upheld because of some form of scholastic or scientific evidence. Dominant culture discounts felt knowledge and instead employs intellectualized knowledge as a means to categorize particular bodies according to its own self-interest. I Amy Carter combats these errant modes of intellectualized knowledge with the knowledge engendered by the lived experiences of the bodies dominant culture has successfully marked—effectively making visible the real consequences generated by the frameworks that mandate invisibility.

The following chapter details the genesis of I Amy Carter from its Punk and feminist roots to the perpetuation of white, middle-class, male-centered, heteronormative ideologies in the 1980s and early 1990s that Riot Grrrl sought to combat. It also recounts some of the factors in Carland's personal life that led to the creation of I Amy Carter, 
including the ramifications incurred on her self-perception by insidious, intellectualized forms of "knowledge" that labeled her a transgressor. 


\section{CHAPTER III \\ THE GENESIS OF I $\bullet$ AMY CARTER}

\section{Part I: From Punk to "Postfeminism"}

Riot Grrrl descends from a long line of dissidents_-it is Punk, it is feminist, and in many cases it is queer. The movement built its unique identity based on many of the resistant foundations of these subversive cultures including a do-it-yourself attitude and politics that rebel against the oppressive status quo. But Riot Grrrl also added its own agenda to the mix, influenced by its opposition to the repressive neo-conservative environment of the 1980s and early 1990s. This chapter traces the genesis of $I \bullet A m y$ Carter in two sections. Part I starts from the rebellious inception of Punk in the 1970s and carries through to the creation of Riot Grrrl in the late 1980s and early 1990s. It details how Hardcore Punk alienated girl Punks, queer Punks, and Punks of color ultimately compelling them to cultivate their own Punk scenes. It describes the agendas

of Riot Grrrl and Queercore, indicating how both movements influenced I $\boldsymbol{\vee}$ Amy Carter; it also enumerates some of the significant political issues that plagued contemporary American society during Carland's formative years, including neo-conservatism and the notion of "post" feminism. 


\section{Punk's Cut-and-Paste Identity}

Punk has always been a refuge for social misfits. The movement was formed in the early 1970s by disaffected American and British youth who loathed pop culture and were disappointed by the institutionalization of once rebellious Rock music. ${ }^{8}$ At its inception, Punk's only ethic was do-it-yourself (DIY), a principle which made Punks active producers of their own identities rather than passive consumers of the normative, alienating mainstream. ${ }^{9}$ It also cultivated a "cut-and-paste" aesthetic as Punks pulled from any number of sources to construct their unique subculture. Aside from a general spirit of resistance, Punk's revolutionary attitude, along with its discordant aggressive performances and sound, drew upon French romantic poets of the late nineteenth century, the American Beat generation of the 1950s and 1960s, and the music and stage antics of Iggy Pop and The Stooges during the 1960s and 1970s (Spencer 2005: 231-234). The movement's iconic tattered, grimy style—-eather jackets and ripped shirts and jeanswas co-opted from New York street culture and is also embodied in the aesthetic of its album artwork and zines (Spencer 2005: 232). As time progressed, a variety of factions inevitably emerged from within the movement and mandated their own guidelines. But Hardcore Punk was the division that ultimately incited Punk's largest internal rebellion.

\footnotetext{
${ }^{8}$ Rock bands like The Rolling Stones had initiated a revolution in the 1960s with their subversive music, but as the decade progressed, their rebelliousness began to wane in favor of profit and a "rock star mentality." Many teenagers and young adults were disenchanted by this shift and angry that accessibility to rock music had been co-opted in the name of capital. Punk Rock was created in direct opposition to the tidy packaging of corporate music and encouraged every Punk who felt like s/he had something to say to pick up an instrument and form a band, regardless of musical aptitude (Spencer 2005: 227-229).

${ }^{9}$ Despite its rebellious attitude, Punk was still a formulaic subculture that required a level of conformity. Guidelines such as one's politics and her or his physical aesthetic mandated whether or not s/he was actually Punk.
} 


\section{Hardcore Punk's Hardcore Aggression}

Hardcore Punk exploded onto the American scene in the early 1980s as a rebellion against another Punk offshoot, New Wave. Steven Blush, a former Hardcore band promoter, asserts that "at its best, New Wave attempted to retain the power and conciseness of Punk while mixing in a plethora of arty 'isms"” (2010: 14). New Wave's "art-school baggage" in combination with its commercial success was too mainstream and too bourgeois for "extreme" Punk kids (Blush 2010: 14-15). Instead, they created their own genre in which they could continue Punk's rebellious agenda and rage against the conservative political and ideological environment of the 1980s. Hardcore appealed to droves of young American rebels-its simplified musical compositions and straightforward lyrics were accessible to virtually any Punk — but its propensity for aggression particularly suited young men.

Slam dancing became the ultimate marker of authenticity at Hardcore shows. ${ }^{10}$ The dividing line was simple, those who enthusiastically slam danced were Hardcore, those who did not were "posers" (Blush 2010: 24). Sara Marcus describes slam dancing as "catnip for boys" and posits that another reason Hardcore was so popular is because slam dancing provided young men with an outlet "to blow off adolescent steam" in an environment where aggression was not only acceptable but also encouraged (Marcus 2010: 49). In their efforts to prove legitimacy to their peers and release pent-up anger, Hardcore boys created an ultra-macho climate that literally pushed girl Punks to the sidelines. Queer Punks and Punks of color were also marginalized when Hardcore NeoNazi Skinheads arrived on the scene.

\footnotetext{
${ }^{10}$ Slam dancing is quite literally the kinetic slamming of arms, legs, and bodies into other arms, legs, and bodies within a designated area called a circle pit, mosh pit, or pit.
} 
Blush attempts to downplay incidences of discrimination within Hardcore, citing the presence of women, queers, and people of color as proof that the scene was really not as bad as some have made it seem. But the manner in which he describes their presence and the ways in which he attempts to excuse the actions of Hardcore white boys only reiterate assertions of rampant prejudice. Blush writes that most girls in the scene were not active participants and were often viewed by the guys as "distractions, [and] even interlopers" (2010: 36). He places the women that were allowed to be involved in Hardcore into two categories; those who were allowed in the pit and those who were allowed backstage. The former were "nasty, ugly trolls" and "asexuals" who embraced a "tomboy ideal"; and the latter, "clichéd big-haired bitches sucking dick backstage" who were evidently only good for sexual gratification (Blush 2010: 36-37). Many of the women Blush interviews on the subject corroborate his designations. Some refused to take part in ongoing misogyny and left Hardcore, while another woman, Laura Albert, said "I did what I had to do," and continued to offer her body in order to remain a part of the scene (Albert quoted in Blush 2010: 36-37).

Hardcore was inundated with an "us versus them" mentality that pitted its own members against one another (Blush 2010: 38). The general consensus is that when one Punk said Hardcore was one thing, another Punk would argue that it was the complete opposite. Hardcore Punks were divided in opinion on everything from drugs and alcohol to religion. When Hardcore Neo-Nazi Skinheads began to grow in number, there was further division within the movement regarding sexuality and especially race. Violence at Hardcore shows was not uncommon but many Hardcore Punks began blaming the brutality on the Neo-Nazi Skinheads. They called them out in their zines and lyrics for 
their racist and hostile behavior, further fueling an already tense and, for many, frightening environment (Blush 2010: 32-35).

D.H. Peligro, black drummer for the band Dead Kennedys, recalls how people were surprised to discover that he was black when they showed up to shows- there were no photographs of the band on their records. He also remembers Neo-Nazi Skinheads shouting "ace of spades!" at him as they were attempting to run him down (Blush 2010: 35). Pete Stahl of the band Scream describes how Neo-Nazis in the crowd at their shows would shout "nigger" at their black bassist Skeeter Thompson. He continues, "But that gave us the opportunity to stand up and say something about it. In a scene that was definitely segregated, we were a statement against that mentality. We'd confront them from the get-go" (Stahl quoted in Blush 2010: 35).

Blush describes Neo-Nazis and other intolerant white members of Hardcore as "fucked-up but smart white kids" who were victims of a "bummer [post-war, post-social movement] legacy"; a legacy that resulted in an economic decline that ultimately caused these kids to react violently as they "seethed with hatred for outsiders stealing jobs and ruining neighborhoods" (2010:32). Blush attributes aggression toward queer Punks to intolerant attitudes and closeted Punks trying to protect their true sexuality (2010:39). Hardcore gay men were more prevalent in the scene than women and, unlike girls, gay men were allowed to be members of Hardcore bands. Although gay sex and gay sexual acts involving straight men were not uncommon practices, and some Hardcore queers were open about their sexuality, the scene was definitely safer if one remained discreet. Gay-bashing was not an uncommon practice in and around Hardcore gatherings, although 
Blush claims that all Hardcore violence toward queers was perpetrated by Neo-Nazi Skinheads (Blush 2010: 38-39).

Not every Hardcore Punk was a chauvinist, racist, queer-bashing white boy. A number of women, people of color, and queers participated in the scene with little or no complaint about the environment in which they were steeped. However, Hardcore's extremely volatile atmosphere ultimately ossified white, male-centered, heteronormative ideologies, eventually becoming so alienating that it compelled large numbers of marginalized members to cultivate their own scenes.

Among the women alienated were Kathleen Hanna, Tobi Vail, Allison Wolfe, Molly Neuman, and Jen Smith who in 1991, in response to growing misogyny both inside and outside of the Punk community, collectively formed Riot Grrrl. Riot Grrrls perpetuated a feminist Punk agenda of girl love through their attitude, their music, and especially their zines. While the mainstream believed Riot Grrrl was more naïve than radical, many young women believed in its power and took the movement very seriously. Grrrls were so serious and steadfast in their beliefs that by the late 1990s the movement dissolved due to internal conflict. Regardless of where one stands with regard to the movement, it is remarkable that in less than a decade Riot Grrrl cultivated its own unique and enduring identity. Only the most significant of social movements stand the test of time, especially considering the rate at which dissenters are stamped out by dominant culture. Through creative effort and sheer will, Grrrls created an environment in which they could engage in critical conversations about their lives as young women in white, classist, male-centered, heteronormative America during the 1980s and 1990s. 


\section{"Riot = Not Quiet": Grrrls Refuse to be Silenced}

Riot Grrrls employed their music, zines, and bodies as a means to protest a number of issues including: discrimination based on gender, sexuality, class, and race; physical, mental, and sexual abuse; and also to advocate for the agency and empowerment of girls and women. The imagery, writing, and attitude of Riot Grrrls functioned as a means to regain agency over their bodies and identities and to protest against and offer new alternatives to the normative roles of women laid out by conservative postfeminist thought of the 1980s and early 1990s, which I will discuss in more detail further below.

Grrrl zines operated as amplified extensions of Riot Grrrl feminism. Taking a cue from their Punk forbearers, these DIY publications functioned in direct opposition to mainstream media, creating identities rather than co-opting those in popular culture that were readymade, conventional, and, in the eyes of Riot Grrrls, harmful. The Grrrl zine distribution network, Riot Grrrl Press, stressed the importance of DIY Grrrl zines in a flyer mailed out in 1993:

Self representation [is important]. We need to make ourselves visible without using mainstream media as a tool. Under the guise of helping us spread the word, corporate media has co-opted and trivialized a movement of angry girls that could be truly threatening and revolutionary...it has distorted our views of each other and created hostility, tension, and jealousy in a movement supposedly about girl support and girl love. In a time when Riot Grrrl has become the next big trend, we need to take back control and find our own voices again. ${ }^{11}$ (Farnsworth and Reinstein 1993)

\footnotetext{
${ }^{11}$ May Summer Farnsworth and Erika Reinstein founded Riot Grrrl Press in the spring of 1993 (Dunn and Farnsworth 2012: 142). Riot Grrrl Press did not intend to take individuality or the DIY process out of Grrrl zines. Instead it was meant to bolster the Riot Grrrl community, functioning as a centralized distribution and networking service. Riot Grrrl Press volunteered to take on the monetary burdens and time constraints that often come along with producing a zine. Grrrls need only provide their zine "flats" (the originals from which photocopies were made and
} 
The pages of Grrrl zines are filled with a mixture of hand-written, hand-drawn, and cut-and-paste elements. Some of the writing and artwork is original—creations of either zine creators or their special contributors. Other content is appropriated from mass media outlets and recontextualized — simply through its presence in the zine or by annotation that is often witty, sarcastic, or repudiating. The material found in Grrrl zines is frequently personal and private. Their content ranges from humorous and light-hearted to deeply emotional. In addition to their personal stories, Grrrl zinesters engage in conversations about politics and popular culture, stressing the importance of continual education (formal and informal) and speaking up. Riot Grrrl's emphasis on DIY, the ways in which they rework the imagery and aesthetic of popular culture, and their insistence on making their voices heard attempts to spotlight and then reject the reiteration of normativity promoted by contemporary socio-political agendas. Grrrl zinesters created a space in which girls and young women with non-normative identities could feel safe to express themselves while also being supported by a like-minded community.

\section{Queercore Unites LGBT Punks}

Queercore precedes Riot Grrrl by around six years, but both arose out of the same disenchantment with growing hostility in the Punk community. Desiring to be active producers of culture rather than marginalized, passive consumers, both movements were also devoted to Punk principles of self-representation through DIY music and zines. In 1985, lesbian musician and filmmaker, GB Jones, and gay filmmaker and photographer,

then stapled to create the actual zine) and the Riot Grrrl Press would then consolidate and distribute all contributions providing easier access to the zine and the Riot Grrrl community. 
Bruce LaBruce, co-authored the first issue of the queer zine, $J D s$, which is heralded as "the catalyst that pushed the Queercore scene into existence" (Spencer 2005: 39 and 41). Queer Punks were shunned by the larger Punk community on the basis of their sexuality but they also felt ostracized by the restrictive conditions of mainstream gay culture. GB Jones recalls that she, LaBruce, and their other queer Punk friends had been kicked out of nearly every gay bar in Toronto because they did not dress or act according to mainstream gay standards. She elaborates, "We didn't subscribe to the racism and misogyny and their ridiculous segregation of the sexes, either. Plus we were poor" (Jones quoted in Spencer 2005: 40). In 1989, Jones and LaBruce contributed an article to Punk zine Maximumrocknroll, called “Don't Be Gay,” in which they vilified the gay movement— gay Punks included—for segregating the sexes by "privileging fag culture over dyke" and also gay men in particular for "acting straight" in an effort to fit in with heteronormative culture (Spencer 2005: 277-278).

LaBruce explains that the AIDS crisis of the 1980s prompted an increase in political activity in the gay community, but after the crisis settled down in the 1990s there was a shift in mainstream gay politics toward "acquiring more and more rights, [and] essentially to become increasingly like the average heterosexual" (LaBruce quoted in Spencer 2005: 277). This included "[dropping gay signifiers] in favor of a less offensive uniform" and "[becoming] much more bourgeois and materialistic" (LaBruce quoted in Spencer 2005: 278). Queer Punks were systematically alienated from mainstream gay culture for embracing unconventional aesthetics and politics, but neither did they desire to be a part of what they viewed as assimilation. They also refused to be defined by the Punk underground solely on the basis of their sexuality. 
Jones, LaBruce, and a number of other queer Punks used outlets like zines and music to foster an environment in which they could come together, be creative, and vocalize a Queercore agenda. Personal narratives are not as frequently employed in Queercore as they are in Riot Grrrl but they do exist and are very powerful. ${ }^{12}$ Queercore tends to center its focus on embracing multivocality. In addition to creating a space for queer Punks, the creation of the Queercore zine $J D s$, for example, was also meant to serve as an example to the gay community of how important it was for all queer people, but especially gay men and lesbians, to come together and to be supportive of one another. Jones and LaBruce wanted the community to understand that it could not possibly "[impose] rigid gender segregation while at the same time [celebrate] gender fluidity" (Spencer 2005: 277). Events like the queer zine festival SPEW and Queercore concerts were also meant to foster environments that celebrated queers from every walk of life. ${ }^{13}$

Like their Queercore counterparts, Riot Grrrls chose DIY because it meant a firm grasp on self-representation. Both groups were equally invested in illuminating unfair (largely male) heteronormative practices, but unlike Queercore Punks, Riot Grrrls were less interested in breaking bread with their male allies than they were promoting an environment of girl-girl love. I Amy Carter is one exception to this "girls only" rule. As a queer Grrrl zine, it serves as a prime example of how the relationship of Queercore, Riot Grrrl, and third-wave feminism could be symbiotic.

\footnotetext{
${ }^{12}$ The Team Dresch song "Don't Try Suicide” from their 1996 album Captain My Captain, for example, details a battle with depression and a crippling fear of life and death.

${ }^{13}$ There were a total of three SPEW gatherings. SPEW I was held in May of 1991 in Chicago. Spew II was held in the spring of 1992 in Los Angeles. SPEW III, to which Carland sent copies of $I \vee$ Amy Carter, was held in May of 1993 in Toronto, Canada (Spencer 2005: 46).
} 
Carland was undoubtedly interested in the same issues as most other Grrrls, but as a lesbian she was also interested in the concerns of the LGBT community. I $\boldsymbol{\vee}$ Amy Carter is filled with her personal geek-outs about Queercore bands Team Dresch and Fifth Column, as well as proclamations of love for some of their members. ${ }^{14}$ She and many other Grrrls were exposed to Queercore because K Records, an Olympia-based independent record label, produced albums for a number of Riot Grrrl and Queercore bands. Carland was committed to Riot Grrrl feminism but because she is also a lesbian, her identity issues were more layered and complex than the average Grrrl. As a result, she was more interested in vocalizing the full spectrum of LGBT experience than in simply sticking to girl love, which meant she allowed queer men to contribute to $I \boldsymbol{\vee}$ Amy Carter and she promoted male queer zines like Hippie Dick. ${ }^{15}$

While Queercore Punks and Riot Grrrls were putting together concerts and holding what were essentially consciousness-raising meetings, many conservatives were continuing campaigns that demonized the socially transgressive. In 1992, Christian Coalition leader Pat Robertson shared his feelings on the proposed Equal Rights Amendment by commenting that feminism is "a socialist, anti-family political movement that encourages women to leave their husbands, kill their children, practice witchcraft,

${ }^{14}$ Carland dated Kaia Wilson from Team Dresch for a number of years and they eventually coestablished their own Queercore record label, Mr. Lady Records.

${ }^{15}$ In $I \vee$ Amy Carter \#4, Carland's friend Ian Carter contributed a poem called "RAPESEX MANIFESTO" in which he describes his mixed emotions about being raped by his father or a man who he calls "daddy" (Carland January 1994: 12). In issue \#3, Carland features a drawing by Keith Mayerson, titled "PINOCCHIO THE BIG FAG," beneath a passage she wrote (discussed further below) titled "BANNED IN CANADA" (Carland Summer 1993: 24). The image depicts the Disney character, Pinocchio, in a crazed state. His wooden hands are on fire, his infamous nose has grown into the area where his penis would be (if he had one), and he has a deranged look in his eyes with a wide grin on his face. In I $\bullet$ Amy Carter \#2, Carland shares a photograph of two young men reading I $\boldsymbol{\vee}$ Amy Carter \#1 captioned, "Sissy Boyz $\bullet$ Amy Carter" (Carland March 1993: 9). In issue \#5, she also includes several fan letters written by male readers (Carland Summer 1994: 30-32). 
destroy capitalism, and become lesbians" (Robertson quoted in Marcus 2010: 186).

Robertson's statement echoes the sentiment of many conservatives at the time, but it also illustrates why it made sense for the LGBT and feminist communities to be allies. If this was how their communities were being presented to the public then it was clear that they were combating many of the same adversaries. Riot Grrrl and Queercore were a part of these larger movements, only they brought with them a unique DIY attitude and Punk aesthetic that provoked conservative talking heads, drew attention to their own movements, and continue to inspire a younger generation.

The Future of Feminism in the 1990s

In December of 1989, Time magazine posed a provocative question to its American readers - "Is there a future for feminism?"16 Much had occurred in the decade following second-wave feminism's public rallies for social equality. During the 1970s, the second-wave fought and won many rights including legal abortion and educational accessibility. Reveling in these victories, many white, middle-class women of the 1980s exchanged their aprons and days full of domestic tasks for business suits and a nine-tofive job. Unfortunately for these women and many others, legal acknowledgements were

\footnotetext{
${ }^{16}$ The article is titled, "Onward, Women! The Superwoman is Weary, the Young are Complacent, but Feminism is Not Dead. And, Baby There's Still a Long Way to Go" (Wallis et al. 1989). The cover of this issue features an image of a sculpture of a woman in a business suit holding a baby in one arm and a briefcase in the other. The sculpture is roughly carved out of wood and adds a harsh, hard-edged quality to the woman. The headline on the cover reads, "Women Face the '90s. In the '80s they tried to have it all. Now they've just plain had it. Is there a future for feminism?" The messages imparted by the image and text on the cover and the actual title of the cover story are clearly contradictory. This is just one incidence of the mass media's manipulation of the public's view on feminism and the working woman. For a comprehensive analysis of Time's mixed-message, see Amelia Jones' essay "'Post-Feminism'A Remasculinization of Culture?" (2000), which I refer to briefly, further below.
} 
simply not enough to convince the public that women's participation in the non-domestic workforce was justifiable.

Debates over the future aims of feminism brought members of the second-wave into conflict with one another. The movement's essentialist inclinations were challenged as feminists of color asserted that the idea of unity diminished their experiences of oppression. This division was the point of contention that ultimately precipitated the culmination of second-wave feminism toward the end of the 1970s and the beginning of the third-wave and notions of intersectional feminism during the 1980s. Combating the gendered binaries that implicated women as subordinate emotional nurturers oversimplified the plight of women. Instead, borrowing from the writing of feminists of color, the third-wave would complicate the very idea of gender, examining how gender intersects (hence "intersectional" feminism) with race, class, and sexuality.

The third-wave's intersectional approach was not compatible with the persistent dominant cultural ideologies that were perpetuated by neo-conservative socio-political agendas and further fueled by mass media. In a sense, Time answered its own question by posing it in the first place—no, there was not a future for feminism. ${ }^{17}$ Popular media outlets such as Time magazine, which were supposed to remain objective, pushed the public to believe that women attained equality in the 1970s and that the women of the 1980s exploited this equality to the point of dissatisfaction and resentment. The (mostly white) women Time included in their exposé supported its conjecture that (white) women

\footnotetext{
${ }^{17}$ In the 2013 documentary film The Punk Singer, Kathleen Hanna recalls the moment she brought this article to Carland's attention and describes how they both were deeply affected by it. They were floored by Time's question. To them, feminism could not possibly be dead because they were "living it, doing it, thinking it, feeling it" every day (Hanna in The Punk Singer 2013). Time's article ultimately reiterated to Carland and Hanna how critical feminism was to the wellbeing of women and galvanized their efforts through Riot Grrrl.
} 
of the 1980s "tried to have it all" and "now [on the brink of the 1990s] they've just plain had it" (Wallis et al. 1989). ${ }^{18}$ After a decade of experimentation in the workforce, white women of the $1980 \mathrm{~s}$ - women of color had been in the workforce for decades by the time this article was published-had apparently begun to see the error of not only the secondwave's agenda, but also the intentions of feminism as a whole. The women's movement had purportedly duped an entire generation of women proving only to be "women's own worst enemy" (Faludi 2006: 2). Phrases like "the feminist mistake," "[a generation of] human sacrifice," and "the great experiment that failed" were thrown around by women columnists in mainstream media to describe the second-wave and the women that followed suit (Faludi 2006: 2). In a matter of twenty years, something had gone terribly awry. But the supposed divide between "real" women and feminists looked very different depending upon which side of the social strata one chose.

\section{The Rise and Fall of Women's Rights from the 1970s-1990s}

The second-wave feminist movement secured a number of victories for women in the mid-twentieth century, including issues related to discrimination, subjugation, and safety; better access to legal counsel; and control over their bodies and minds. ${ }^{19}$ Two of

\footnotetext{
${ }^{18}$ From evidence in the article, I have inferred that a majority of the women with whom Time spoke for this exposé were middle-class and white- the magazine does not make their race or class explicitly clear. The authors of this article only identify one woman, out of the many with whom they spoke, specifically as black, and the survey Time administered to gather women's opinion on feminism refers to its participants as simply "adult women." Many of the women the article quotes are identified as college students who attend Ivy League or notoriously expensive colleges such as Brown University. The only other instances in which the article specifically mentions race and class is when the authors use feminism as a scapegoat for larger political issues such as working women's lack of access to childcare.

${ }^{19}$ It is not my intent to oversimplify the many victories won for women by second-wave feminists. For the purposes of this paper, I am focusing only on a handful of victories that correlate with the plight of women who, like Carland, were labeled transgressive by conservative postfeminist thought due to class, sexuality, and/or gender; women who were either offered
} 
the largest triumphs for the bodies of women in the 1970s were the court case Roe $V$ Wade and the legal acknowledgment of marital rape. Before these interventions there were legal restrictions and socio-cultural frameworks in place that bound women to unwanted pregnancies and abusive marriages. Social stigma and unwritten rules-such as the "rights" of a husband over his wife's body - that were secured by the institution of marriage attempted to keep women in line with the status quo. The persistence of the second-wave ultimately paid off and women's bodies were finally protected under the laws of the United States. The Women's Educational Equity Act was also a benchmark for the advancement and rights of women. Not only did this law prevent women from being typecast into positions in elementary and secondary education, it also pushed for the advancement of girls and women in extra-curricular activities such as school sports and advocated for the expansion of education and research in women's studies.

The second-wave is often accused of being a movement of and about the issues of white, middle-class women. Many of these criticisms are warranted; however, it is important to acknowledge the second-wave's attempts at striking down the patriarchal governance of bodies that transgressed the boundaries of white, middle-class, malecentered, heteronormativity. The Equal Rights Amendment (ERA) was originally written by Alice Paul in 1923. The ERA held that "equality of rights under the law shall not be denied or abridged by the United States or by any state on account of sex." In theory, this simple statement would apply to all women. Both the Alice Paul Institute and the ERA Task Force of the National Council of Women's Organizations emphasize the role of increased pressure from organized women's groups of the second-wave for the passing of protection by the government in the 1970 s only to have it threatened by socio-political agendas in the 1980s and 1990s; or women who were only ever vilified and never protected at all. 
the ERA through Congress in 1972. Unfortunately, legal acknowledgement of rights such as those set forth in the ERA do not come without their challenges. Despite repeated attempts over the past forty years, the ERA still has not been ratified by fifteen states. The reluctance of these states to sanction an amendment that was conceived ninety years ago speaks to the many complications that lie behind the seemingly simple notion of equality of the sexes. The concept of second-wave feminism is also marked by such complexity. Continued social ruptures at the end of the 1970 s continuing through the 1980s inevitably led to public backlash against the advances made by the secondwave and feminists, in general.

\section{The Reagan Administration's Initiates a Rigid Neo-Conservative Environment}

Ronald Reagan's election to the presidency in 1981 fostered a neo-conservative environment that would have devastating effects on women, feminism, and the LGBT community for decades to come. His political agenda is often described as being antiwomen - an assertion that is vehemently denied by Reagan, members of his Cabinet, and his conservative supporters. Reagan's appointment of the first woman, Sandra Day O’Connor, to the Supreme Court in 1981 is generally cited as evidence against this. However, the policies he supported during his political career indicate otherwise.

The Reagan administration's first blow against women's progress was the removal of the Equal Rights Amendment from the GOP platform upon his election to the presidency in 1980 (Francis). Rather than back amendments interested in the preservation of women's rights, Reagan adamantly supported legislation such as conservative Human Life Amendments. In addition, his staunch endorsement of the traditional, nuclear American family was not only evidence of his belief that women 
should remain in submissive domestic roles; it also demonstrated his disapproval of homosexuality. During his presidency, Reagan backed the Hatch Amendment which proposed that "a right to abortion is not secured by [the] Constitution" (NCHLA 2004: 2). He also supported the Family Protection Act which, if enacted, would have "banned intermingling of the sexes in any sport or other school-related activities, required that marriage and motherhood be taught as career choices for girls... and banned legal aid for women seeking a divorce" (Burk 2004). The appointment of federal judges by Reagan and his successor George H.W. Bush had even further reaching consequences.

Reagan and George H.W. Bush's presidencies transformed federal judiciaries and the Supreme Court from "never more than moderately liberal, into a predominately conservative institution" (Zinn 2005: 574). Reagan's appointment of conservative judge William Rehnquist to Chief Justice of the Supreme Court in 1986 resulted in "a series of decisions that weakened Roe $v$. Wade...prevented doctors in federally supported family planning clinics from giving women information on abortions, and said that poor people could be forced to pay for public education (education was not 'a fundamental right')" (Zinn 2005: 574). Furthermore, in 1991, George H.W. Bush appointed African American conservative, Clarence Thomas to the Supreme Court—a man who had been openly accused of sexual harassment by his assistant, a young female law professor, Anita Hill (Zinn 2005: 574). Political moves such as these reveal a lack of concern for the health and overall protection of the rights of women as well as the rights of the poor. The Reagan administration's reaction to the AIDS crisis of the 1980s is also indicative of harsh indifference, this time toward the health and well-being of the gay community. 
On June 5, 1981, the United States Centers for Disease Control and Prevention (CDC) released a newsletter that described five cases of male homosexual patients in Los Angeles who were demonstrating unusual symptoms of pneumonia. The next day, The San Francisco Chronicle printed an article based on the CDC's findings titled "A Pneumonia That Strikes Gay Males." Less than a month later on July 3, another article about the outbreak appeared, this time in The New York Times, titled "Rare Cancer Seen in 41 Homosexuals" (Bronski 2011: 224; and Eaklor 2008: 174). Despite the fact that by the end of the year the CDC had identified a number of straight men with the same unusual symptoms, AIDS had already been labeled a gay disease (Bronski 2011: 224). Religious and political conservatives latched on to this definition, vilifying the gay community for the existence of AIDS.

Televangelist Jerry Falwell claimed, “AIDS is not just God's punishment for homosexuals. It is God's punishment for the society that tolerates homosexuals" (Falwell quoted in Bronski 2011: 226). ${ }^{20}$ Pat Buchanan, one of Reagan's senior advisors, wrote that "AIDS is nature's retribution for violating the laws of nature" (Buchanan quoted in Bronski 2011: 226). Perhaps even more alarming than these cutting remarks was Reagan's complete silence on the issue - it took four years for him to publicly acknowledge the disease (Eaklor 2008: 175).

When he finally did break his silence in 1985, Reagan claimed that AIDS research was a top priority for his administration and that the federal government had allocated

\footnotetext{
${ }^{20}$ Falwell was a Christian fundamentalist preacher and co-founder of Christian-based political lobbyist group, the Moral Majority. The Moral Majority were anti-Equal Rights Amendment, anti-homosexuality, anti-abortion, anti-pornography, and anti-feminist. During the 1980 presidential election, Falwell campaigned cross-country on behalf of Reagan. His support and the support of the Moral Majority are widely credited for Reagan's win (WGBH Educational Foundation 2010).
} 
over a half billion dollars to the cause since 1982. As detailed in an exposé written by journalist Daniel Beegan in 1985, Representative Gerry E. Studds, an openly gay congressmen, criticized the President's supposed concern wondering aloud why it had taken him so long to speak publicly on the subject. Studds also looked into the federal government's AIDS research funding and discovered that the Reagan administration had only requested the allocation of $\$ 213.5$ million over the past five fiscal years. Only after increased pressure from Democratic Representative Henry Waxman did the administration request more funds. Based on Representative Studd's inquiry into the matter, Beegan determined that by the end of the fiscal year in 1986, the federal government was in line to spend a potential \$389 million on AIDS research since 1982significantly less than Reagan's claim (Beegan 1985). By 1990, 31,129 people died from AIDS (Bronski 2011: 228). Had it not been for grassroots efforts like Larry Kramer's ACT UP (the AIDS Coalition to Unleash Power), there is no doubt that the spread of AIDS and the number of AIDS-related deaths would have been even more devastating. It seemed that any allocation of funds for groups of people or programs that strayed from conservative conceptions of morality suffered—including women and children in need.

Reagan was notorious for his use of the degrading term "welfare queen" and, predictably, his policies involving welfare and other social programs did little to support them. During the first four years of his presidency, Reagan allocated billions of dollars to the military. In order to cover this increased expense, $\$ 140$ billion of funding for social programs was cut (Zinn 2005: 577). Free school lunch programs were downsized to the point that one million children "who depended on the meal for as much as half of their daily nutrition" went without (Zinn 2005: 578). The national poverty level at this time 
ranged around an income of $\$ 900$ a month—Reagan's policies cut welfare benefits down to a harrowing \$500-\$700 a month (Zinn 2005: 578). Furthermore, one-third of Reagan's budget cuts directly affected government programs that mainly aided women and children, even though the funds allocated to these programs only comprised ten percent of the federal budget (Faludi 2006: 9). By the end of his first four years in office, two million female-headed households and almost five million women had fallen below the federal poverty line (Faludi 2006: 9).

Unsurprisingly, public sentiment toward welfare programs remained largely hostile. Many people were unaware of how their taxes were actually applied to federal spending and many were not privy to the fact that military spending took a much larger percentage of their taxes than welfare (Zinn 2005: 579). Even after the end of the Cold War with the dissolution of the Soviet Union, billions of tax dollars were still allocated to the military budget (Zinn 2005: 592). In 1992, despite a survey which revealed that fiftynine percent of Americans desired a decrease in military spending, Congress voted against the allocation of $\$ 120$ billion from the military budget to support human needs. Instead, the money was spent to protect Europe against a dubious Russian attack (Zinn 2005: 584).

In addition to adverse legal policies, this political era was marked by the silencing of political dissenters through the elimination of the Fairness Doctrine in the mid-1980s. This doctrine held the Federal Communications Commission accountable for ensuring fair coverage of all sides of controversial public issues (Zinn 2005: 564). As a result, by the time of George H.W. Bush's presidency in the 1990s, the airwaves were permeated with conservative radio talk shows that paid no heed to liberal interests or 
concerns (Zinn 2005: 564). Liberal activists were obscured in this environment but they continued to battle against their conservative silencers. Howard Zinn describes their task as a "[struggle] uphill, against callous political leaders, trying to reach fellow Americans most of whom saw little hope in either the politics of voting or the politics of protest" (2005: 565). Despite dissenting activists' greatest efforts, conservatism's dominance over society remained steadfast and was reinforced by its dissemination through mainstream media. Widespread conservative ideologies only exacerbated negative assumptions and opinions of feminism and the women who transgressed traditional, white, middle-class, male-centered, heteronormative American gender roles. The future of feminism appeared to be overwhelmingly grim.

\section{The Perpetuation of Postfeminism}

The mass media's constant reiteration of white, middle-class, heteronormative male ideologies stoked the fires that continued to burn feminism. Time's (rhetorical) question is a prime example of how the conservative notion of postfeminism infiltrated the masses. Popular culture and conservative political leaders posited that second-wave feminists had attained equality in the 1970s and, as a result, the United States was now in a state of "post" feminism. This term appears to be politically impartial—simply stating that Americans moved on "after" the second-wave-however, the unattractive portrayal of feminists perpetuated by politicians and the mainstream media encouraged a general loathing of the word feminism and its associated politics - a practice that continues today to an almost identical effect.

For many people, the word feminism evokes a stereotypical understanding of (particularly) the second-wave as a radical, unified movement of angry women with hairy 
legs who "precisely articulated [an] attack on the American [nuclear] family" (Jones 2000: 10-11). Clearly, these types of descriptions imbue feminist women with a fearful disposition. Postfeminism did not simply indicate the end of "radical" second-wave feminism, as conservative politicians would have Americans believe. Rather, it marked political attempts at ending any and all forms of feminism; or, as Amelia Jones argues, attempts to "remasculinize" culture.

In the essay “'Post-Feminism'-A Remasculinization of Culture?” (2000), Jones analyzes what she describes as an "insidious project currently at work to disarm feminists"; a project spearheaded by politicians, mass media, and postmodern thought, hidden beneath the guise of "post" feminism (2000: 19). Jones contends that in the 1980s and 1990s there was a push to absorb feminism into masculine culture, in turn "negating feminism's specific political power-its perceived potential to undermine the theoretical certainties that continue to validate American cultural discourses..." (2000: 8). She then elaborates upon how the remasculinization of culture functions through conservative postfeminist thought.

The mainstream media alleged that the women in the 1980s who exchanged their domestic roles for an outside job had abandoned their families. As a result, "women's work" had to be absorbed by men so that life at home would not fall into irrevocable chaos. The remasculinization of culture served to keep the power-balance in favor of men through the simultaneous championing of the normative roles of wife and mother, and by threatening women with having their "natural" and "respectable" roles usurped (Jones 2000: 8-10). This tactic is even more alarming because it excluded entire sectors of "other" American women. Women of color and the working-class had held jobs long 
before the second-wave's demands for workforce equality in the 1970s. Work was not optional for these women because a paycheck meant the survival of their families, regardless of their marital status. The prizing of a woman's singular role in an American nuclear family also completely discounted same-sex and other non-traditional families. Political policies and social ideals ultimately punished the bodies that transgressed their ascribed boundaries. These sentiments were only reiterated in larger society through mass media outlets like Time, creating a vicious circle of guilt, blindness, and false retribution.

As a feminist, a lesbian, and a member of the welfare-class, Carland was directly affected by the perpetuation of these insidious practices. The following section details some of the significant events in Carland's life that led to the creation of I Amy Carter. It also enumerates some of the ways in which oppressive frameworks impacted her identity.

\section{Part II: Tammy Rae Carland's Personal History}

$I \checkmark$ Amy Carter was heavily influenced by the histories discussed above, but Carland's personal experiences during her formative years were equally influential. Part II of chapter III provides a brief account of Carland's life, focusing on her impoverished upbringing and the ways in which her social status directly impacted the rest of her life. I begin with a short biography and then venture into a discussion of an essay Carland wrote in graduate school called "Allowing a Little Class to Leak Out (the puddle under the table)." This essay elucidates Carland's difficulties grappling with her transgressive identity and provides a basis for understanding how she works through these issues in $I$ 
Amy Carter. I conclude the chapter with a discussion about Carland's reasons for producing her zine.

\section{A Brief Biography}

Carland was born in 1965 in Portland, Maine, where she spent much of her childhood. As a welfare kid living in Section 8 housing, Carland recalls having often been the subject of local photography students out on street shoots. The culmination of her first-hand experience of the appeal of working- and welfare-class subjects in documentary photography occurred in the 1980 s while applying to a local art school. ${ }^{21}$ Featured in the school's catalog was a student's social documentary portrait of two children - Carland and her younger sister—at a basketball court in their government subsidized neighborhood. Carland describes this instance as her first experience of being the subject of a work of art (Carland and Cvetkovich 2012: "Part 5"). She was accepted into the school and a few days into her photography class, another social documentary portrait of a family member was featured; this time of her mother sitting at the bus stop outside of the fish factory at which she worked. Carland describes these experiences as having "[indoctrinated me] to be the subject of art and not the artist from day one" (Carland and Cvetkovich 2012: "Part 5"). Her understanding of people's varied interest in and expectations of her as a member of welfare-class society extends deeper than

\footnotetext{
${ }^{21}$ Carland makes a distinction between the working- and welfare-classes based on her personal experience. She writes, "It seems that people have this vision of a romantic working class pride that has nothing to do with growing up on welfare in this country...I did not grow up 'working class' - there is a certain pride that is afforded to the working class that the 'non-working class' doesn't have access to. The working class position themselves far outside of the welfare and homeless class" (Carland Summer 1994: 11). As Carland indicates, welfare-recipients are shamed by their necessity to receive government assistance. From the point of view of the public, even the poorest of the working-class deserve dignity because they have the drive and determination that the welfare-class reportedly lack.
} 
artistic practice. It is tied up with her impoverished upbringing in Portland, Maine in the 1970s and early 1980s as well as her experiences in college from the mid-1980s to the early 1990s.

During her senior year in high school, Carland's guidance counselor was "dumbfounded" when Carland sought her out for advice on applying for college (Carland Summer 1994: 11). Although she was one of the brightest students in her graduating class, her counselor suggested she seek more lucrative career options that would help her and her family survive. Despite her counselor's advice, Carland continued on to college. In 1991, she obtained her Bachelor of Arts from Evergreen State College in Olympia, Washington — the geographical hub of Riot Grrrl subculture. While working toward her undergraduate degree, Carland became good friends with classmate Kathleen Hanna.

Hanna's considerable involvement in the burgeoning Riot Grrrl scene would eventually make her a figurehead of the movement. She fronted one of Riot Grrrl's most well-known bands, Bikini Kill, and was a co-creator and contributor to a number of popular and formative Grrrl zines including Bikini Kill and Revolution Girl Style Now. Carland and Hanna's friendship had a clear effect on Carland's involvement with Riot Grrrl. Before Hanna sang for Bikini Kill she sang in a band with Carland and their friends Heidi Arbogast, and Greg Babior called Amy Carter. The band eventually parted ways but Carland's involvement with Riot Grrrl and Amy Carter carried over into her creative and political ventures as a Master of Fine Arts student at the University of California, Irvine, where she began her own Riot Grrrl zine, I Amy Carter. ${ }^{22}$ In 1995, a

\footnotetext{
${ }^{22}$ The connection Hanna and Carland formed in college did not end with the dissolution of their band, Amy Carter. In 1993, Carland collaborated on the artwork for Bikini Kill's album Pussy Whipped on which was featured a song called "For Tammy Rae." In addition, Carland wrote a
} 
year after completing her MFA at the University of California, Carland was accepted into the Whitney Museum's prestigious Independent Study Program in New York City. In 2002, she became Associate Professor of photography at California College of the Arts, where she continues to teach today.

From 1996 to 2005, Carland and Kaia Wilson co-ran an internationally recognized independent record label and video art distribution company called Mr. Lady Records. Carland's website describes Mr. Lady as "dedicated to the production and distribution of queer and feminist culture" (Carland: "Bio"). The label released a number of albums including two by Kathleen Hanna's Le Tigre, and three by Wilson's own band, the Butchies. ${ }^{23}$ As mentioned earlier, Carland is a practicing artist. She has exhibited her photographs, videos, and mixed-media work internationally. In addition, she has curated photography exhibitions and video art screenings and has edited and contributed reviews, articles, interviews, and commercial work to a number of international publications. Carland has also produced album artwork for Bikini Kill, the Fakes, the Butchies, and Kaia Wilson's solo project. Her photographic work has been featured in a variety of books including The Passionate Camera: Photography and Bodies of Desire (1998) and Lesbian Art in America (2000). "(the puddle under the table)"

In 1993, halfway into her graduate career, Carland wrote a paper titled "Allowing a Little Class to Leak Out (the puddle under the table)." In this essay, Carland uses the

page-long feminist editorial in Hanna's honor in I $\boldsymbol{\vee}$ Amy Carter \#3 titled "4-Kathleen I (heart) U" (discussed further below). She also thanks "Kathleen," "Heidi," and "G.B." (most likely in reference to Hanna, Arbogast, and Babior) in the credits of a few issues of I Amy Carter. ${ }^{23}$ Aside from singing and playing guitar for Team Dresch and the Butchies, Wilson has also released two solo albums. Much of the content addressed in her music deals with queer and lesbian issues. 
analogy of an apartment building to describe the defining aspects of her identity, writing: "Apartment \#1 [is] the academic/artist brain, apartment \#2, the lesbian body, apartment \#3, the poor white trash belly...it goes on and on, it is a full house" (Carland 1993: 3). Like many of the private aspects of a tenant's life that manage to seep through the walls and windows of an apartment building — the scents, the sights, the sounds—Carland's experiences of shame, pride, conjectured truths, and lived realities, too, leak out of the apartment that contains her "white trash belly" and into those that house the other parts of her being. I Amy Carter functions as the communal space where all of these fragments gather to converse.

Carland begins this essay by asserting that "it has become increasingly imperative to complicate identity politics rather than present a reductive equation that [answers] the most pedantic questions" (1993: 2). She articulates this complexity, writing:

An identity is the convergence of history, experience and practice. It is lived through the tropes of race, class, gender, and sexual identity...the personal interrogation of ones own matrix of identity and how one is placed (or places herself) within social political relationships [is most useful]. Clarity is always ideological and reality is adaptive and relative. (Carland 1993: 2)

The reality of Carland's lived experience as a white, feminist lesbian — and especially as a person whose life has been so marked by extreme destitution — is a reality that she admits, in this essay and in $I \vee$ Amy Carter, she oftentimes has difficulty revealing to others. She asserts that no one ever truly wants to know what it was like growing up so impoverished, but if someone did she would tell them that "it was/is debilitating, humiliating, frightfully close to death, and closeted in shame" (Carland 1993: 4). The reason others do not want to hear this truth, Carland maintains, is because her lived experience awakens a dormant shame that reveals a contrast to their own lives. This 
reciprocal revelation prompts others to try to relate to a life that they can never truly understand. Almost apologetically, people try to congratulate her for persevering and coming out on top at the other end. "What people don't seem to understand or be aware of" she writes, "is that there is very little space for pride when you are characterized as aberrant and even abject" (Carland 1993: 8).

Carland ends her paper with a short discussion on what she calls the "mandated and managed silence of the poor" (1993: 10). Here she begins to reflect upon the fact that her silence concerning her harrowing past does not simply serve to protect her family and herself. She concludes, "My silence...keeps those who are not, or have never been poor safe. It also keeps us other, at a distance, something to be reckoned with. As of lately I'm not so afraid of the reckoning" (Carland 1993: 10; emphases original). The newfound bravery Carland touches upon in this essay is evident within the writing and imagery she presents in all five issues of $I \boldsymbol{\vee}$ Amy Carter. While her essay focuses mainly on the poor "other," I $\bullet$ Amy Carter takes issues of (in)visibility and identity a step further, encapsulating the experiences of "others" with regard to white, middle- and upper-class western norms of gender, sexuality, and sometimes race. I $\boldsymbol{\vee}$ Amy Carter also functions as the space in which Carland's own processes of identity-construction are made evident.

In $I \vee$ Amy Carter \#4, Carland shares a shortened revision of "Allowing a Little Class to Leak Out (the puddle under the table)," now titled "JUST CUZ THE FRUIT BOWL MAKES IT TO THE TABLE DOESN'T MEAN IT'S THE CENTERPIECE (the puddle under the table)" (Carland January 1994: 27-28). Her inclusion of this essay in her zine (and the fact that she also submitted it for publishing in the Grrrl zine Girl 
Germs) is a further indication of her unwillingness to remain silent on such subjects.

Although she confesses in these essays that she still struggles with shame, she also expresses that she truly believes, as do other Riot Grrrls, that revealing the "untidiness" of her lived experiences will help fight the insidious powers that try to keep her reality and the reality of a number of other women invisible. She employs $I \vee$ Amy Carter as the venue to initiate this tactic.

Tammy Rae Carland, Identity, and I $\vee$ Amy Carter

As a young woman in the 1980s and early 1990s, Carland's identity was comprised of a complicated mix of her past and present experiences and the person she both perceived herself to be and desired to become. By the time she entered college in the mid-1980s, Carland had already endured two decades of social stigma rooted in extreme poverty, a transgressive sexual orientation, and burgeoning Riot Grrrl feminist beliefs. As she continued her education, her class identity, as perceived through the lens of mainstream society, inevitably shifted from welfare- to middle-class. Regardless of her involuntary change in social status, there was no loosening of Carland's kinship to her impoverished roots. Even today she still feels very connected to and affected by her former class-status. ${ }^{24}$

\footnotetext{
${ }^{24}$ In the Queer Conversations on Culture and the Arts program held at California College of the Arts in September 2012, Carland points to one instance of the far-reaching effects of her welfareclass childhood. She shares that she could never employ documentary photography with human subjects as part of her artistic practice because she was so often the subject of this genre when she resided in Section 8 housing as a child. As mentioned above, she describes that in those moments she was "[indoctrinated] to be the subject of art and not the artist" (Carland and Cvetkovich 2012: "Part 5"). Instead, much of Carland's photographic work speaks to the (in)visibility of the human subjects who are not pictured. Lesbian Beds from 2002, for example, features images of the unmade, empty beds of (single and committed) lesbians. These photographs ultimately humanize a group of marginalized people by showcasing a banal, everyday part of life to which almost any person can relate.
} 
Carland began to produce $I \boldsymbol{V}$ Amy Carter as an escape from the intense

coursework of graduate school, but it was also about creating a sense of community in a new place. ${ }^{25}$ In a tagline on the back of each issue, she describes this zine as "a fanzine for the weak of heart. It's about having butterflies in your belly and biceps in your brain. It's about girl love + girl power + girl sex + and girl friends...It's part National Inquirer part Dear Diary and part whatever the fuck I feel like" (Carland March 1993 and Summer 1993: back cover). Like many people caught up in a contemporary cultural moment, Carland collected zines and created her own without any foresight of historical importance. She saved these items for two reasons; she professes that she is just the type of person to save things she feels are important, but she also saved them out of a love for items that are "a material witness to our personal lives" (Carland and Cvetkovich 2012: "Part 3"). She continues, "It's not like I had a sense of 'This is really important work!' But I knew, there is a fiber in me that knows...this material stuff that culture creates is really important" (Carland and Cvetkovich 2012: "Part 3").

For Carland, one of the most important attributes of $I \bullet$ Amy Carter during its production was its ability to help her keep in contact with the network of friends she left behind in Olympia (Carland 1997: 22). Similarly to scholars on the subject, Carland describes the general function of zines, including $I \boldsymbol{\vee}$ Amy Carter, as a way of communicating with other people, a way of disseminating information, and a way of

\footnotetext{
${ }^{25}$ Zines are alternative media and their circulation reflects this. Some of them are free, some are traded, but most of them cost a few dollars to help cover the cost of production. They are passed along person-to-person, at social gatherings such as concerts, conventions, and political meetings, at independent bookstores, through zine distribution networks such as the Riot Grrrl Press, through the mail, and, more recently, they can also be purchased online. I $\boldsymbol{\vee}$ Amy Carter mainly circulated through the mail or person-to-person. All that Carland required was two or three dollars and a self-addressed, preferably stamped, envelope. Zine creation is not a moneymaking venture; it is a labor of love.
} 
creating networks and friendships (Carland and Cvetkovich 2012: "Part 3"). I Amy Carter conforms to this basic framework, but it also performs a demanding task that is inherent in many personal zines; it functions as a counterpublic sphere for the marginalized. Carland's zine, in particular, makes visible a number of members of American society who were ignored and alienated by dominant cultural apparatuses in the early 1990s. In effect, I Amy Carter deconstructs, analyzes, and illuminates oversimplified notions about identity that are based on convention. It engenders a space for the articulation of lived experiences, making way for the (re)construction of more accurate, complex identities. While her girlhood crush on first-daughter Amy Carter appears to be the basis of this zine, it is really Carland's own identity as a poor, white, Riot Grrrl feminist dyke that is the flesh, blood, and beating heart of her endeavors. "Allowing a Little Class to Leak Out (the puddle under the table)" contains another illuminating passage that describes the influence Punk had on Carland's life. She describes the Punk scene as "the space where the aberrant and abject got to flourish and refuse to be stifled in shame" (Carland 1993: 8). She continues:

At a good [Punk] show, when it works, the audience is equally involved in the dynamics of expression. The audience has elaborately constructed rituals of movement, dress, dance, and socializing...[Punk] is about discursive space, a space that is unwilling to be fixed, defined with singular meaning, or absent of contradictions... of all the projects of cultural production I exist in this is the one I do so with the least amount of fragmentation. (Carland 1993: 8-9)

Although in this essay Carland's discussion of Punk is contextualized within a larger discussion of poverty, it is clearly related to Riot Grrrl feminism and is also applicable to the other aspects of her identity. 
When analyzing all five issues of $I \vee$ Amy Carter as a counterpublic sphere, specific processes of identity construction are revealed. Carland effectively (re)constructs her own identity while also contributing to the ongoing production of Riot Grrrl identity by synthesizing personal histories and experiences with analyses of the normative boundaries of mainstream culture, ultimately creating composite selves. These composite identities and the physical properties of Carland's zine-as-object are significant. Both (re)create something new, although still fragmented, by sifting through memories and material ephemera and then selecting and pasting together relevant or interesting pieces. The seams created by the layering of these disparate elements are also significant because they indicate that identity is a continual and ever-changing process that is informed by a myriad of factors rather than the ready-made, static conventions dominant culture imposes.

Chapter IV traces these seams through Carland's visual and textual representations of gender, sexuality, class, and race and the ways in which insidious oppressive frameworks mark the bodies that do not conform to their ideologies. It also analyzes Carland's methods of articulation to determine whether she ultimately subverts or reifies existing normative boundaries. Ultimately, I Amy Carter demonstrates that fragments do not always signify deficiency. Just like the physical properties of the zine itself, the events, impositions, and personal elements that comprise identity are perfectly capable of producing a new and functional entity. 


\section{CHAPTER IV \\ $I \vee A M Y C A R T E R$ AS A COUNTERPUBLIC SPHERE}

Riot Grrrl's world of public intimacy is inundated with slogans, stories, lyrics, and works of art that make tangible Grrrls' experiences of navigating the normative conditions of gender, sexuality, class, and race. Cvetkovich designates these impositions by dominant culture as insidious traumas because they are able to successfully implement normalizing frameworks without attracting much attention (2006: 46). Grrrls shared their narratives of alienation to let other Grrrls know that they were not alone in their fight and to also use their stories as a means to illuminate discrepancies between mainstream "truths" and lived realities. In the eyes of Riot Grrrls, as Nguyen indicates, because these stories conflicted with mainstream accounts, Grrrls' testimony effectively transformed into (traditional) authentic knowledge and served as subversive political acts. Nguyen maintains that this tactic is too narrow to elicit any effects - that the better method is to question the structural dimensions of oppression. I agree that determining the origins of discrimination and the mechanizations that keep these injustices in place is indeed invaluable; however, this stratagem does not offer much to those who, in the meantime, are being oppressed.

Insidious traumas do not just generate physical effects - like gay-bashings - they also elicit psychic consequences. Cvetkovich proposes that publicly expressing the 
effects of negative experiences can produce counterpublic spheres in which the disaffected can engage in positive dialectics. These counterpublic spheres foster spaces in which people with similar experiences can safely interact with one another, effectively generating small-scale instances of collective histories or cultural memory. Cvetkovich elaborates, "[This] turn to memory is also a turn to the affective or felt experience of history as central to the construction of public cultures, to give a range of people the authority to represent historical experience, and often to implicitly suggest a plurality of points of view" (2006: 37). In other words, counterpublic spheres imbue the alienated with the power to make their experiences tangible and therefore visible. Once manifested, these shared experiences indicate the complexity of lived reality and the ability to persevere. These intimate acts effectively generate the types of dialogue that address and illuminate institutionalized oppressive practices — an outcome that Nguyen would have liked to see from Riot Grrrl. The material artifacts of these counterpublic spheres, such as zines, function as the evidence needed to support the demand for change in established systems.

$I \vee$ Amy Carter is Carland's counterpublic sphere and she used it as a platform to elucidate social injustices as well as to celebrate the many components of her transgressive identity. She was unafraid to express that she was proud to be a woman, proud to be a dyke, and proud to be a feminist, regardless of who that knowledge offended or how hard dominant ideologies strived to hinder her. She was also enraged by the fact that these characteristics made her inferior in the eyes of mainstream society. Carland communicated her feelings and point of view in $I \vee$ Amy Carter visually and textually, oftentimes combining the two for added effect. She employed explicit 
language and imagery, sarcasm, lots of humor, and reclaimed distorted notions of the many facets of her identity in order to make her point. Some of the visual elements and written compositions in $I \vee$ Amy Carter are capable of standing alone to express Carland's perspective and to elucidate affective experiences - her appropriation of Rosie the Riveter, for example, is a clear signifier of girl power. However, in the context of a zine, the relationship between visuals and text is truly interdependent—each is directly affected by the presence of the other in a number of ways.

The aesthetic of I Amy Carter immediately defines the manner in which it is received. Even today, its simultaneously girly and gritty aesthetic attracts young women, girl Punks, and (wannabe) Riot Grrrls and its queer imagery draws people from the LGBT community. The subject matter Carland and her contributors address in their writing is received differently than it would be in any other periodical simply by its presence in her zine. Because $I$ Amy Carter is an alternative form of media, and especially because of its queer Riot Grrrl aesthetic, Carland's readers expect discourse about topics that are minimally addressed or completely overlooked by the mainstream, as well as dialogue that is radical in comparison. The imagery in I Amy Carter is meant to enhance the zine's written content as well as represent visually Carland's stance on sexism, homophobia, classism, and racism. However, in certain instances there are disconnects between what she says about these issues and the visuals she presents.

This chapter examines the ways in which Carland addresses gender, sexuality, class, and race visually and textually in I Amy Carter. It is divided into three sections: part I discusses gender and sexuality; part II, race; and part III, class. I employ Cvetkovich and Nguyen's analyses of public intimacy as a framework to critique the 
efficacy of Carland's zine as a counterpublic sphere that attempts to illuminate institutionalized oppressive practices. I examine the relationship between text and image, ultimately revealing Carland's successes and struggles with implementing intersectional identity.

\section{Part I: "FUCK YOUR GENDER": I $\vee$ Amy Carter, Gender, and Sexuality}

In the west, biological sex is often equated with gender. This corollary has become so strong over the years that even the toys with which children play are policed by stringent boundaries. ${ }^{26}$ Western culture has also forged an arbitrary connection between biological sex, gender, and sexuality. Although it has been slowly shifting in recent years, the heteronormative environment of the United States dictates that one's gender or biological sex automatically determines the (opposite) gender or biological sex of her or his partner-women are meant to partner with men and men with women. This environment not only predetermines the sexual preferences of its citizens, it also outlines the parameters of sexual activity so that women are slut-shamed for promiscuity while men are high-fived by their friends for every new notch on the bedpost. For reasons such as these, discussions of gender and sexuality in Riot Grrrl culture and $I \vee$ Amy Carter often overlap.

The insidious policing of sex and gender also regulates the aesthetic, mannerisms, daily activities, and authority of gendered bodies. The Riot Grrrl Press excerpt shared in part I of chapter III indicates evidence of such guidelines. The mainstream media could not take Riot Grrrl seriously as a political movement because they perceived them as just a bunch of disgruntled teenaged and college-aged girls. They were right about one thing;

${ }^{26}$ A little boy, for example, would likely be chastised by his peers and many adults for playing with a "feminine" toy like a baby doll. 
Riot Grrrls were angry_-but not in the frivolous manner the media alleged. Grrrls were tired of dominant culture — white, middle- and upper-class, straight men-imposing unfounded rules on their bodies and not taking them seriously when they objected. Their anger was dismissed as a flippant, harmless expression because the rules of female gender do not allow such defiant gestures any authority. Riot Grrrls recognized this baseless mentality and, in response, intentionally employed exaggeration. They appropriated tropes of gender and sexuality, such as cuteness and sexual naivety, and either inverted the expectations of the categories completely or applied them in the most acidic and aggressive ways they could muster. They screamed in their songs, they flaunted aesthetics that were hyperfeminine, hypermasculine, hypersexualized (or some combination of the three), and they swore and raged like no other. A single page in $I$ Amy Carter \#3 sums up the Riot Grrrl attitude precisely. Covering the entire page in oversized, capitalized letters is the statement: "FUCK YOUR GENDER" (Carland Summer 1993: 25). Riot Grrrl and Tammy Rae Carland refused to take any more shit.

In this section, I begin with an analysis of how the physical properties of $I \boldsymbol{\vee}$ Amy Carter reflect the Riot Grrrl aesthetic and attitude. I then cite specific examples from the zine to discuss the relationship between Carland's visual and textual representations of the ramifications of misogyny and how she attempts to reclaim authority over gendered, sexualized, and queered bodies by embracing the words, notions, and images oppressive frameworks use to shame them.

I $\boldsymbol{\vee}$ Amy Carter's Visual Representation of Gender and Sexuality

$I \vee$ Amy Carter is saturated with imagery that signifies gender and sexuality. Its overall aesthetic is typical Riot Grrrl - it is sugary-sweet and hyperfeminine at first 
glance, but caustic and confrontational upon closer investigation. The covers of $I \boldsymbol{\vee} A m y$ Carter alternate in pastel shades of pink, blue, yellow, violet, and green and its pages are embellished in a way that resembles the aesthetic of the diary or scrapbook of a teenage girl. Collaged amongst personal narratives are clippings such as photographs of celebrities, film stills, and articles that have been collected from various periodicals. There are also appropriated and hand-drawn cartoons as well as handwritten annotations (sometimes in loopy cursive). Many pages are trimmed with decorative borders and frames, doodles of hearts and the symbol for female gender $(q)$, and a profusion of clipart flowers and stars.

But $I \vee$ Amy Carter is also interspersed with elements that are aggressive, provocative, and evoke difficult emotions. There are clip-art guns and chainsaws; sexualized images; and words and phrases in emphatic capital letters like "POISON GIRLS," "SLUT," and "DYKE" are pasted repetitively throughout. The zine also features images of girlhood and femininity that have been modified so that what once represented naivety and submission now radiates knowingness and authority, and sometimes articulates the physical and psychological consequences of misogyny, homophobia, and abuse. Many of the narratives and annotations in I $\boldsymbol{\vee}$ Amy Carter recapitulate these expressions. They detail textually the many incarnations of lived experience that can sometimes be difficult to represent visually.

"The Truth is..."

Every issue of I Amy Carter opens with a note from Carland that usually details what she has been up to since the last publication, the concepts she has been thinking about as of late, and sometimes talks about the trajectory of the zine. Other writing 
includes poems about life and love, reproductions of columns from mainstream news sources, and passages that detail goofy stories or ruminate on serious social issues. Many of Carland's narratives reveal a different side to her hardened Riot Grrrl exterior-a vulnerability that manages to emanate strength and tenacity. This writing confronts insidious traumas through cerebral and articulate meditations that are written in a way that maintains accessibility, and it is further supported by visual expressions that condemn the consequences of these surreptitious frameworks. Narratives and images such as these are the type of tangible testimony to which Cvetkovich alludes when discussing the formation of counterpublic spheres.

A page from $I \vee$ Amy Carter \#1 features a modified, full-page image of three young women that reflects Carland's cynicism toward and disapproval of misogynist ideologies. The young women are dressed in short nightgowns and their bodies are framed from the waist down so that only their bare legs, gently folded hands, and a single partial upper-body, including breasts, are visible. The absence of the young women's heads and faces imparts an eerie quality to the image, rendering the bodies almost inhuman. Their demure poses and the ways the fingers on each of their hands lightly touch and intertwine endows them with a subservient, lady-like character. Carland enhances the feeling of submission by pasting the phrase "assume the position" on top of their bodies (December 1992: 15). Because the young women are in their nightgowns and because the way the image is framed has reduced what were once people into truncated body parts, this image can also be read as if the women are waiting to be fucked, and not in the pleasurable sense—-fucked as in sexually violated, fucked as in screwed by the system, fucked by their ascribed gender roles. In a passage from $I \checkmark A m y$ 
Carter \#3, Carland elaborates upon the ways in which women are fucked because they are positioned as subordinates and objects for consumption.

Carland frequently discusses the idea that assertive and intelligent women are too often labeled and depicted negatively. In an essay titled "4-Kathleen: I (heart) U," she slams the people who harass her friend, Kathleen Hanna, for speaking out against the political and social injustices enacted upon women, queers, the poor, and minorities. Carland begins by describing how she, herself, is often labeled as "angry, rageful, too intense, a big mouth, too serious, cold, hard to get close to, judgmental" and then launches into a page-long enumeration of the issues Hanna addresses for which she is also criticized (Summer 1993: 28). She explains:

The truth is that there are 17 lesbians on death row - one of them for killing seven white male rapists. The truth is that there are a million little girls in a million different places all over the world who are at this very minute clenching their bodies tight so that some adult male can't invade, enter, rape them. The truth is that there is some teenage girl giving her boyfriend head because she thinks she has to in order to keep his love. The truth is that a woman is standing on a street corner trying to sell her food stamps for money so that she can buy a bus ticket away from the father/brother/husband/boyfriend who beats her bloody and bruised. The truth is that none of the women in my family make more than $\$ 7,000$ a year and most of them have minor dependents. The truth is that some girl is stripping, dancing, laying down money so that she can pay for her college tuition. The truth is that some young woman is coming out to her family only to be disowned for the rest of her life. The truth is that there is a woman who is pulling the trigger to prevent another rape/beating. The truth is that this woman will most likely go to jail. The truth is that a woman is being denied access to shelter or a job because she is not white. The truth is that every breath I take with ease is the last breath for a person who is sick with AIDS. The truth is that every time I walk down the street I get assaulted by tongues that are comfortable in calling me bitch - whore - cunt, the tongues of strange men. The truth is that behind my back there are tongues that are comfortable calling me bitch - whore cunt, the tongues of men who are not strangers. The truth is that woman are starving to death in so many different ways and for so many different reasons. (Carland Summer 1993: 28) 
Carland concludes, "if these truths don't speak to your reality then consider yourself fortunate and don't conspire to keep down and apart those of us who feel it necessary to voice the rage and tell our own truth" (Summer 1993: 28).

As Cvetkovich notes, engagement with the psychic ramifications incurred by experiences such as those Carland articulates above functions differently in counterpublic spheres. Typically, these affects are treated as a condition that must be resolved (effectively made invisible) through some sort of treatment. But in counterpublic spheres like I Amy Carter, these affects are kept visible through multiple modes of interaction and are also made meaningful (Cvetkovich 2006: 19). In passages such as "4-Kathleen: I (heart) U," Carland demonstrates to her readers that the instances she describes are so effectively obscured by dominant culture that they are on the verge of becoming permanently invisible (Cvetkovich 2006: 23). By beginning each of her sentences with the statement "The truth is," Carland signifies that the information that follows has either been viewed as erroneous or has been entirely overlooked. In addition, the negative comments about Carland and Hanna that initially sparked this passage illustrate an already rampant state of invisibility—-people would not feel the need to tell them they are overreacting if they were not constituents of compulsory blindness. By detailing so many instances of inequity and pointing to their requisite invisibility Carland is not only defending the outspokenness of her friend, she is also supplying evidence to validate her own need and the need of others to be forthright about these issues. Carland reiterates her assertions visually through images like that of the three truncated young women discussed above. 
Cvetkovich also suggests that just because psychic affects are oftentimes emotionally toxic does not mean that responses to them must also be negative. Counterpublic spheres allow room to embrace consequences that are meant to be hurtful which, instead of perpetuating antagonism, can generate positive expressions or even cause for celebration. Shame is one of the affects to which Cvetkovich alludes with which Riot Grrrls and especially Carland are very familiar. She asserts that the reclamation of shame offers an alternative method for building identities and communities that are not simply created in reactionary opposition to discriminatory frameworks (Cvetkovich 2006: 47). The perpetually shifting meaning of slang and vernacular is an example of this tactic in action.

\section{Reclaiming Derogatory Terminology}

Heteronormative and misogynistic culture is notorious for its distortion of language. It adopts expressions, terminology, and entire concepts and then duplicitously employs them within the parameters of its framework so that telling someone they throw like a girl, or calling them a pussy, a fag, or a dyke becomes offensive. After being used in this manner for so long, not only can these expressions and their associated connotations engender shame, they can also become invisible to the point that they are unwittingly subsumed into culture. However, they can also be re-appropriated by those they were meant to injure in the first place. Carland enacts this tactic through the reclamation and re-positioning of the notions associated with the words "pussy," "dyke," and "slut" so that they are read anew as terms that emanate power, pride, and authority.

To express "girl power" Carland shares traditional images such as Rosie the Riveter, but she also frequently evokes the expected obscene rebelliousness of a Riot 
Grrrl. Occasionally, she even adds humor to the mix. In $I \bullet$ Amy Carter \#2, amongst a collage of images - including a photograph of two young men reading the first issue of $I$ $\boldsymbol{\vee}$ Amy Carter labeled "Sissy Boyz $\vee$ Amy Carter" and trading cards of Princess Leia from Star Wars and Amy "Triple A" Amanda Allen from The A-Team-is an appropriated clipping from a mainstream periodical which features two photographs, one of Amy Carter and the other of Chelsea Clinton, both holding their pet cats (Carland March 1993: 9). Carland modifies the image by pasting "POISON GIRLS" on top of it and "PUSSY POWER" just underneath. She also pastes two clip-art hands on either side of "PUSSY POWER," which point at the images of Carter and Clinton, just in case her readers are not clear to whom or what she is referring.

Carland takes the shame out of the use of the word "pussy" in slang by adding the word "power" but also by pointing to the images of Carter and Clinton, whom she admires for their intelligence. ${ }^{27}$ By modifying their images with these phrases, she is also essentially (and humorously) fashioning Carter and Clinton as role models that other Grrrls (and girls) can look up to. She enacts a similar tactic with the word "dyke" and its associated insinuations when used in mainstream culture. Carland uses the word "dyke" frequently when referring to herself and she encourages other lesbians to use the term if they feel it is fitting. In doing so, she is reclaiming a word that has been co-opted and employed maliciously. She also reclaims some of the effects generated by sexist and homophobic insidious traumas in other, simpler ways, such as sharing appropriated pop culture.

${ }^{27}$ Carland makes it clear that she admires Carter through her explanation of Amyness, but she is also a fan of Clinton. A few pages earlier in the same issue, she berates a local DJ for calling Clinton ugly and saying that she and her mother are "too smart for their own good" (Carland March 1993: 17). 


\section{Embracing Tabloid Trash}

Carland alters a majority of the appropriated images in I Amy Carter to indicate the message she is trying to convey—support, celebration, disgust, etc.—but even the images she does not change, but simply chooses to share in her zine as-is, signify her feelings toward feminism, the LGBT community, and the other topics her zine addresses. By sharing photographs of open, closeted, and suspected Hollywood lesbians; stills from films that feature women kissing or strong female characters; and sensational stories and images about queerness that she collects from tabloids and pulp magazines she simultaneously celebrates and makes visible lesbian culture.

Carland was a passionate collector of tabloid exposés that detailed the "bizarre" lives of lesbians and revealed the "shocking" homosexual relationships of Hollywood starlets. Although it seems counterintuitive to lavish attention on trashy pop culture fodder, Carland explains that she clipped and saved tabloid articles because they were some of the only mainstream periodicals that featured lesbians during the 1980s and early 1990s (Carland and Cvetkovich 2012: "Part 3"). If the shame implied in associating with queer culture is not evident enough in titles such as "Strange Town Where Men Aren't Wanted" and "My Naughty Night of Love_-with Another Woman!," the content of these articles certainly makes it clear.

Carland shares a 2-page story from Star magazine in I Amy Carter \#3 that details the secret lesbian life of television star, Kristy McNichol, who, the magazine alleges, became a lesbian after being sexually abused by a female babysitter. ${ }^{28}$ The article portrays McNichol as a gender-bending sexual deviant by sharing "inside

\footnotetext{
28 "My Lesbian Love Affair with Kristy McNichol," Star magazine, April 3, 1990.
} 
knowledge" about her personal life that is divulged by her supposed ex-girlfriend, supermodel Melisande Casey. Casey's description of McNichol's body as "straight as a board" with "no waist, no thighs or behind" is a condescending attempt to diminish her femininity. Casey also makes McNichol sound like some sort of feral creature when she describes a sexual encounter during which $\mathrm{McNichol} \mathrm{bit} \mathrm{her} \mathrm{"like} \mathrm{a} \mathrm{pooch"} \mathrm{and} \mathrm{growled}$ and barked at her "like a dog." McNichol's performance was so convincing, Casey shares, that it beckoned her two dogs. Eventually, Casey was overwhelmed with repulsion at how much of a "hard-core lesbian" McNichol was. She ended their relationship and happily reports to Star that she is elated to have found true love with her new “macho man" boyfriend (Carland Summer 1993: 7).

In issue \#1, Carland features an article from the National Enquirer that describes what life is like in "Lesbianville, U.S.A."—otherwise known as Northampton, Massachusetts. ${ }^{29}$ In the article, the town's growing numbers of lesbians is attributed to two nearby all-women colleges, Smith and Mount Holyoke. The magazine declares that Northampton is "a bizarre town where so many women love women you can even find them cuddling and kissing on Main Street!” It also portrays the town's lesbian residents as hostile toward men, describing how one of the town's bookstores sells buttons that declare "just say no to men," and mentioning that at certain community events men are "NOT" welcome. The lesbians of Northampton do not seem to mind the nickname the town has been given and report feeling safe and welcome in the neighborhood. The town's straight residents are not as pleased with their presence. One man snidely remarks

29 “Strange Town Where Men Aren’t Wanted," National Enquirer, April 21, 1992. 
that he wishes they would leave Northampton and "take their sick lifestyle to San Francisco..." (Carland December 1992: 8).

Thinking about these articles today, when public consciousness, tolerance, and acceptance of queer culture has shifted so significantly, it is difficult to take them seriously_most of the commentary is laughable. However, their sensationalism is significant when you consider, as Carland points out, that these were some of the only mainstream publications that featured lesbians. Even when these articles are subtler with their insinuations they are still dehumanizing. Nevertheless, lesbian culture is Carland's culture and she refuses to let it be co-opted and used to debase the queer community. Instead, she embraces the articles along with their hate-mongering, shame-inducing mannerisms and employs them to point to the existence of lesbians and, in effect, keep them visible. Even with their dark subtexts, even when inadvertently illuminating the harsh treatment to which lesbians are subjected, these articles illustrate the resilience of the queer community. In spite of it all, they still manage to be happy, passionate, and loving people.

\section{“BANNED IN CANADA”: Reclaiming (Queer) Sexual Pleasure}

As indicated by the straight man who resides in Lesbianville, U.S.A., the "lifestyle" of the queer community was viewed by many as an aberration. Dominant culture perpetuated this repugnance with the help of mainstream media and it was also maintained institutionally through laws such as those directed at "deviant" sexual acts like sodomy. ${ }^{30}$ Women were also shamed for showing any inkling of sexual desire; and some of them were automatically labeled tramps depending on their race or class. The

\footnotetext{
${ }^{30}$ In 1986, in the court case Bowers v. Hardwick, the Supreme Court ruled that "there was no constitutional protection for homosexual sodomy" (Bronski 2011: 230).
} 
only good sex was white hetero sex-and only if the female in the equation waited until marriage to have sex, committed to eternal monogamy with her forever husband, did not show too much voracity between the sheets, and the intercourse resulted in a baby or two. In other words, sexual pleasure was reserved for straight white men.

Carland is an adamant supporter of sex-positivity. She combats dominant assertions about sexual pleasure throughout $I \vee$ Amy Carter — namely the fact that it is either treated as a taboo subject or as a sensation strictly reserved for men—by showcasing the many different forms it assumes - that is, intercourse outside of man on woman penetration. She is of course especially interested in representing queer sexuality. An appropriated clipping in I Amy Carter \#1 elucidates a number of ways sexual pleasure can be had. The excerpt comes from the lesbian feminist publication Heresies and describes the "typical week and a half" of the sexual exploits of "Anonymous.", The gender of Anonymous is not clear. Her or his list of sexual experiences is detailed in a way so that all that can be deciphered is that s/he is queer. Anonymous' sexual escapades involve giving and receiving oral sex, fucking, and making love to women, men, women dressed as or pretending to be men, men dressed as or pretending to be women (or more than one of each), fantasizing about the man or woman $\mathrm{s} / \mathrm{he}$ is sleeping with as something other than s/he is, having sex with a woman claiming to be a man who hates queers, and masturbating—all with or without orgasms (Carland December 1992: 14). Through this clipping, Carland expresses to her readers that there are countless ways to engage in sexual encounters, that sex does not always equal penetration by a penis (or

\footnotetext{
${ }^{31}$ Heresies: A Feminist Publication on Art and Politics was published between 1977 and 1992 by the Heresies Collective - a group of second-wave feminist artists. It featured various forms of art and essays that addressed topics through the lens of feminist critique.
} 
any penetration at all), and that what one considers typical or pleasurable is relative. Carland also articulates (queer) sexual pleasure visually.

In I Amy Carter \#5, Carland features a detailed drawing of a lesbian couple engaged in intercourse. One woman, wearing a strap-on dildo, penetrates the other who is masturbating. The expressions on both women's faces indicate that they are enjoying their encounter. The image is captioned at the top "There Are Friendships and...There Are Friendships" and at the bottom "There are friendships with girls that may be some of the best friendships you've ever had" (Carland Summer 1994: 35). This image demonstrates that sexual pleasure is not strictly the domain of heterosexual men. It also offers a visual representation of (queer) sexuality that is not permissible in the mainstream. However, because the image is so explicit, it likely does not work in favor of dispelling notions that label homosexuality perverse. The story Carland tells in $I$ Amy Carter \#3, emphatically titled "BANNED IN CANADA," reiterates the difficulty of combating such beliefs.

Carland details in "BANNED IN CANADA" how two of her friends had their zines, Thorn and Hippie Dick, confiscated at the Canadian border for pornographic content; "Something about representation of anal sex and fist fucking" (Summer 1993: 23-24). She acknowledges that Hippie Dick is definitely a porn zine (one that she "highly recommend[s] to anyone into hairy boys") but she feels that the actions of the Canadian government are homophobic. She writes "that is the premise of these literal/visual border crossing laws isn't it - that is to squelch any expression of anything that is not male female ministry [sic] position procreative sex" (Carland Summer 1993: 23). 
Further along in the passage, Carland reveals that Thorn was confiscated for one particular bit of writing that she herself authored; "a very short but sweet recounting of some good old fashioned lesbo sex" (Summer 1993: 23). "And just for the record," she continues, "it wasn't necessarily fist fucking, three fingers does not a fist make" (Carland Summer 1993: 24). She concludes by conceding that this is neither the first nor the last time she has been or will be censored. Regardless, the entire situation only serves to remind her why she goes through the trouble to create $I \checkmark$ Amy Carter; "because - for the most part zines are things that usually slip through the cracks of the big bad powers that be. And even if they don't at least they get read by more people then just the cops and the bad guys" (Carland Summer 1993: 24).

The reaction of the Canadian government to the presence of queer sex in underground periodicals indicates how sexuality—whether orientation or the act—is policed by dominant culture in a manner that reiterates heteronormative and sexist practices, especially in the unyielding, neo-conservative 1980s. Although Carland jokes about this incident when she tells the story, she still makes it clear that this type of censorship is problematic. The (in)visibility it generates influences the ways others perceive sexualized and gendered bodies as well as the ways in which those bodies perceive themselves. These perceptions run so deeply that they also affect innocuous subjects such as anatomical knowledge.

\section{"GIRL TALK": Reclaiming the Authority of Vulgar Vaginas}

Slut-shaming is another result of insidious frameworks and it has the added effect of designating women's sexual organs dirty and vulgar. This is demonstrated by the use of the word "pussy" as a slang term, but it is also indicated by Carland's inquiries into 
women's lack of knowledge about their vaginas. I Amy Carter \#4 features a two-page spread with an essay written by Carland titled "GIRL TALK" and a visual composition that depicts two identical stippled drawings of vaginas. The drawings are semianatomically correct and show the labia majora and minora, the clitoris, the vaginal opening, and the anus. An ampersand between the images indicates that the dialogue pasted above them represents a conversation between two young women. It reads, "I saw my mother's once, we were in the bathtub"; "Did you touch it?"; "Do you want to touch mine?" (Carland January 1994: 6). By using drawings of vaginas as stand-ins for portraits of the young women, Carland simultaneously (and literally) makes vaginas visible but also begins to point to the issue of women's lack of knowledge about their bodies. Carland further addresses how this ignorance affects women's attitudes toward their bodies and sexual pleasure in her essay.

In "GIRL TALK," Carland discusses her personal struggle with (not) understanding her body and its relationship to pleasure. She describes her body as "an awkward container" that "stored memory and secrets" and "attracted unwanted attention" (Carland January 1994: 5). ${ }^{32}$ She remarks that there is a lot of discussion about the representation of women's bodies but never enough consideration about women's selfrepresentation. Carland attributes this lack of self-reflection to socially constructed fears of women's bodies and especially their vaginas. She describes the vagina as a "simultaneous site of lust/desire and fear/disgust" which has led to an epidemic of

\footnotetext{
${ }^{32}$ As a child, Carland was sexually abused by a family member. She is open about this traumatic event but chooses not to recount her experiences. It is not entirely clear if she does not share the details of this story because she is not ready to, does not want to, or because she does not feel the need to; but in I Amy Carter she copes with this incident by being adamantly sex-positive. This is her way of asserting authority over her body — she is, in effect, reclaiming her right to sexual desire and pleasure.
} 
women who have never even looked at their vaginas, or lesbians who are scared to sleep with other women because they are not confident that they will "know what to do" or are "afraid of feeling too intense and emotionally vulnerable with a body that [is] 'like' theirs" (Carland January 1994: 5). Carland insists that women need to be supportive of one another when issues about their bodies or what has been physically or psychologically enacted upon those bodies arise - regardless of whether or not they can directly relate to these experiences.

The combination of this passage and its accompanying imagery reflects the seriously negative impact sexism and misogyny enact on the bodies of women. These insidious traumas function so effectively that they have virtually monopolized sexual authority to the point that women are fearful of their own bodies. By visually and verbally expressing women's feelings of apprehension about their bodies, Carland illuminates these effects. These articulations - especially the semi-erotically-charged rendering of dialogue between what are effectively two personified vaginas — encourage her readers to recoup sexual pleasure and reclaim agency over their bodies by learning about them through exploration.

As a counterpublic sphere, I Amy Carter allows room to support expressions of the types of sexual pleasure and corporeal knowledge that are otherwise forbidden by sexism and homophobia. Carland employs her zine to help illuminate these insidious frameworks, which operate largely unnoticed by society, administering support to those they affect, and aiding them in their fight against these unjust practices. The writing and imagery shared on each page work to reveal the fissures between the purported truths and lived realities of gendered and sexualized bodies as they simultaneously work to reclaim 
the notions about them that are employed to elicit shame. Some subjects, however, are more difficult for Carland to articulate.

Carland's textual elucidations of her experiences with class, for example, are strong, but she struggles to represent this facet of her life visually. Race is an especially challenging subject for Carland to confront — both textually and through images — but she still makes attempts to address the issue. Nguyen's analysis of Riot Grrrl's race crisis provides a basis from which to understand Carland and other Riot Grrrl's struggles with integrating race into their intersectional practices. Along with Cvetkovich's notions of the positive aspects of public intimacy (via counterpublic spheres), it also helps distinguish the ways in which Carland's articulations of race are different, and somewhat more successful than her Riot Grrrl counterparts.

\section{Part II: "If You're Dissin' The Sisters You Ain't Fighting The Power!!": I $\vee$ Amy}

\section{Carter and Race}

Riot Grrrls enact public intimacy through the voluntary sharing of personal stories. These stories are meant to foster a safe, supportive community and to serve as collective resistance to societal norms. Nguyen, however, argues that these acts are not voluntary, rather they are necessary if one is to receive girl love, and that the reciprocity of such an arrangement was unequal for Grrrls of color. Even so, she does not believe that white Grrrls intended to be disparaging when insisting that Grrrls of color share their experiences as a non-white racialized "other." However, she maintains that they did not

understand the consequences of their demands - that Grrrls of color would feel burdened by white Grrrls' requests and slighted by their naivety on the subject of racialized bodies - and, in many cases, were resistant to what these consequences revealed about 
themselves. Nguyen compares this insistence to historical "desire[s] for access and attachment to racial, colonial others," highlighting the naivety of this tactic as well as its harmful consequences (2012: 174-175).

In this section, I address Carland's visual and textual interactions with race. I begin by elaborating upon Nguyen's discussion of the notion of proximity in Riot Grrrl's world of public intimacy and the ways in which this idea is problematic. I then pull the few specific instances in $I \checkmark$ Amy Carter where race is addressed and examine the disjuncture between Carland's insistence on intersectionality and its lack of representation in her zine. Ultimately, I argue that Carland's articulations of race are unique compared to other white Grrrls, although their scarcity and some of her methods are misguided.

Problems with Proximity

In the world of Riot Grrrl, proximity—one's personal relationship with another person; how "close" two people are—is capable of absolving ignorance, which makes it the key to paving the way to an oppression-free future (Nguyen 2012: 173-174). Nguyen asserts that proximity was also a means for white Grrrls to diminish their "whiteness" and therefore any involuntary claims to privilege. ${ }^{33}$ Grrrls believed that exchanging intimate stories was equivalent to exchanging knowledge. This knowledge unified all parties and also served as proof that the Grrrl who harbored it was not and could not be racist. In cases where Grrrls did not have access to these stories, their desire to be close with a person of color, or expressing shame that they were not, was proof enough of their good

${ }^{33}$ Nguyen notes that rebellious Punk expressions - like dying one's hair blue — were another way to diminish whiteness. By intentionally ostracizing themselves from normative communities, Punks were essentially attempting to align themselves with the "othered" members of society (Nguyen 2012: 182). 
intentions and, therefore, also served to protect them from accusations of racism (Nguyen 2012: 178 and 181-182).

White Grrrls' insistence upon intimacy also frequently drained Grrrls of color physically and emotionally. In addition to being part of the minority in mainstream society, young women of color found themselves in the same position in Riot Grrrl culture. As a result, they were often besieged with requests from white Grrrls to elaborate upon their experiences, which effectively transformed Grrrls of color from participants in the movement to its educators - but only if the information they shared remained at the personal level. Any attempt from a Grrrl of color to critique the conditions of race, especially if that critique implicated a white Grrrl's privilege, was often read as an attack (Nguyen 2012: 180-181). ${ }^{34}$ As Nguyen notes, race was viewed as "a problem of distance" and white Grrrls believed that their attempts to bridge the divide exonerated them (2012: 183; emphases original). They also believed that if other people made the same attempt, racism could be eradicated.

Placing pressure on Grrrls of color to elaborate upon their distinctive racialized histories and then employing the knowledge gained from those stories to serve one's own self-interests is clearly a misguided practice. Furthermore, it reveals an imbalance in the reciprocal relationship of girl love (Nguyen 2012: 182-183). Many white Grrrls used the

\footnotetext{
${ }^{34}$ In July 1993, the first national Riot Grrrl convention was held in Washington D.C. On the second day of the convention an "Unlearning Racism" workshop was held, organized by Kathleen Hanna and co-led by an African American woman from Washington D.C.'s Peace Center. The manner in which the event unfolded still haunts Hanna today. At some point there was a huge debate over reverse racism and a number of white women expressed offense at the suggestion that the idea of reverse racism is misguided. A young woman named Jessica Miller was in attendance that day and she recalls things like "It's not my fault if..." and "I didn't ask to be..." being defensively thrown around by aggrieved white women - they were completely unresponsive to the conversation because it meant that their approach was wrong (Marcus 2010: 162-165).
} 
knowledge they gained about race from Grrrls of color to their benefit — as proof that they were apprised of non-white racialized struggles and better for it—but Grrrls of color received nothing in return. It is understandable to want to know what it is like to experience discrimination based on the color of one's skin; however, simply learning about these experiences is not equivalent to questioning how racism came into existence and why it still survives in contemporary society. Riot Grrrl's lack of acknowledgement of the structural determinations of race was such an overwhelming flaw that it severely divided the movement, eventually causing it to crumble entirely.

Carland's approach to race in $I \vee$ Amy Carter is by no means a perfect example of how white Grrrls should have engaged with the subject, but she does avoid many of the flaws Nguyen enumerates. The biggest drawback to Carland's method is its scarcityrace is one of the issues with which she engages least, both textually and visually. When she does approach the subject, however, she does not depend on Grrrls of color to enlighten her readers by sharing their first-person experiences, and she foregrounds her privilege without inciting shame. Instead, Carland points to the roots of racism by sharing statistics that illuminate the far-reaching consequences of its institutionalization and by prompting her readers with philosophical questions about its existence. In some cases she also uses this information to bring awareness to the communal and personal histories of women of color.

\section{Acknowledging Race through Support and Statistics}

Carland does not speak on behalf of women of color and she does not reflect upon race through personal commentary like she does with gender, sexuality, and class. Instead she relies upon quotes, statistics, and other appropriated ephemera to uncover 
instances of race that are embedded in the lives of the American people as well as the practices of the United States government. These elements are the medium through which she demonstrates her continually developing perception of racialization.

In $I \vee$ Amy Carter issues \#2 and \#3, Carland employs statistics to highlight some of the extreme disparities in the ways culture treats women of color as opposed to white women. ${ }^{35}$ Issue \#2 details the neglect of women of color by the United States government concerning the AIDS crisis. The statistics Carland provides indicate that of all cases of women with AIDS in the U.S., women of color account for $73 \%$ and, in addition, one quarter of these women are Latina. The statistics also reveal that AIDS is the leading cause of death for African American women in a number of regions throughout the U.S. (Carland March 1993: 8). ${ }^{36}$ In issue \#3, Carland reproduces statistics that bring awareness to the disproportionate number of women of color in prison- they represent 54\% of the entire female prison population (Carland Summer 1993: 32). ${ }^{37}$

\footnotetext{
${ }^{35}$ Carland does not indicate the dates these statistics represent but I assume they are contemporary to the zine.

${ }^{36}$ As of 2010 , African American women constitute $64 \%$ of all new cases of HIV infections. White women account for 18\% and Latina women account for 15\% (CDC 2010: "HIV Among Women"). HIV is one of the top ten causes of death for African American women ages 15 to 54 with women ages 35-44 accounting for 7.2\% of deaths and women ages 20-34 accounting for 6.9\% (CDC 2010: "Leading Causes of Death... Black Females"). HIV is also one of the top ten causes of death for Latina females ages 5-9 and 25-44, with women ages 35-44 accounting for $2.5 \%$ of deaths (CDC 2010: "Leading Causes of Death...Hispanic Females"). HIV does not make the list as a leading cause of death for white, Native American/Alaskan, or Asian/Pacific Islander women (CDC 2010: "HIV Among Women").

${ }^{37}$ A study based on statistics from the U.S. Bureau of Justice by non-profit organization the Sentencing Project reveals a recent drastic decline in the disparities between incarcerated white women and women of color: "In 2000, black women were incarcerated in state and federal prisons at six times the rate of white women. By 2009 that ratio had declined by $53 \% \ldots$ This shift was a result of both declining incarceration of African American women and rising incarceration of white women. The disparity between Hispanic and non-Hispanic white women declined by $16.7 \%$ during this period" (Mauer 2013: 2).
} 
By highlighting incongruities through hard evidence like statistics, Carland begins to illuminate the structural determinations of race. This tactic is significant, however, it stops just short of an actual critique. The data Carland shares makes it clear that women of color are inordinately affected by these serious medical and social issues, but she does not provide any more detail that indicates why this imbalance exists—-such as the crimes women of color are imprisoned for, how they have contracted AIDS, or what access they have to medical services. She begins to point to the ways in which institutionalized discrimination concerning AIDS is actually enacted by sharing an informational flyer on the same page, but the information is generalized and does not make important distinctions between race, class, age, etc. Carland's approach to race functions similarly on a page in $I \checkmark$ Amy Carter \#3 that features quotations about visibility and race taken from four feminist writers.

\section{Approaching Race through Appropriated Academic Quotations}

At the beginning of I Amy Carter \#3, Carland writes that she spent part of her summer reading many of the queer anthologies she had been meaning to attend to for a number years. Just a few pages later, she exercises some of the knowledge she has absorbed from these texts by sharing four quotations from four notable feminist poets and scholars that speak to issues of visibility and race. Carland employs the authors of these quotes as vessels through which to encourage $I \vee$ Amy Carter readers to look beyond essentialist feminist tenets. She also challenges the tendency of larger cultural and feminist discourse to overlook difficult and uncomfortable subjects concerning women, especially minorities, which ultimately reiterates their already rampant oppression. 
Carland carefully types and arranges the quotes, providing each with its own frame and detailing the texts from which they were sourced.

The first quote is from Chicana poet, playwright, and feminist activist Cherríe Moraga. It is a small excerpt from a chapter entitled "From A Long Line of Vendidas" from Moraga's emotionally intense book about growing up as a lesbian Chicana called Loving in the War Years: Lo Que Nunca Pasó Por Sus Labios (1983). Carland hones in on a simple yet powerful line, "What would a movement bent on the freedom of women of color look like?" (Moraga quoted in Carland Summer 1993: 4). Moraga's question is a reflection of the evolving feminist consciousness of the 1980s. Ultimately she asks women of color to consider the possibilities if they looked to their own cultures for the tools to fight oppression as opposed to working within the boundaries that are imposed upon them by dominant, white culture.

The second quotation comes from Japanese-American poet, scholar, and feminist activist Mitsuye Yamada's contribution to This Bridge Called My Back (1981). In her essay, "Invisibility is an Unnatural Disaster: Reflections of an Asian American Woman," Yamada writes, "We must remember that one of the most insidious ways of keeping women and minorities powerless is to let them talk only about harmless and inconsequential subjects, or let them speak freely and not listen to them with serious intent" (Yamada quoted in Carland Summer 1993: 4). Yamada recognizes the importance of articulation as well as the significance of support when a woman is brave enough to raise her voice; especially when the subject she addresses may be difficult and unpleasant to discuss. But just as Carland and other Grrrls demonstrate with the creation 
of their zines, these processes can be a significant means of coping with an oppressive past.

The next quote is from Caribbean-American poet, essayist, and feminist activist Audre Lorde. Taken from a chapter in her book Sister Outsider (1984) called "Age, Race, Class, and Sex: Women Redefining Difference," the excerpt Carland shares reads, "Somewhere, on the edge of consciousness, there is what I call a mythical norm, which each one of us within our hearts knows 'that is not me"” (Lorde quoted in Carland Summer 1993: 4; emphases original). The mythical norm Lorde speaks of is the model American — the white, straight, middle-class male; the American that need not hyphenate his identity; the American with implied power. Typically, anyone who falls outside of this archetype works to assimilate its characteristics so as not to risk punishment for violating the ascribed standard. In the case of women, assimilating equals submitting to the conditions of their gender role as dictated by the bearer of authority. Conversely, Lorde suggests affirming diversity and complicating the generic concept of identity to better address and combat the oppressive practices.

The fourth and final quote is from white American lesbian poet and essayist Adrienne Rich. The excerpt is taken from an essay called "Some Notes on Honor: Women and Lying” from Rich's book On Lies, Secrets, and Silence: Selected Prose, 1966-1978 (1979) and promotes open dialogue between women. It reads, "Our future depends on the sanity of each of us, and we have a profound stake, beyond the personal, in the project of describing our reality as candidly as we can to each other" (Rich quoted in Carland Summer 1993: 4). Having spent too many years in the shadows of a maledominated society, the diverse experiences of countless numbers of women have been 
continually discounted and overlooked. Rich believes that feminism may suffer the same fate if women continue to describe their plight in simplified terms that ultimately marginalize minorities. Only when each woman acknowledges the benefits and disadvantages of her differences will the feminist movement successfully represent and battle for true equality.

These excerpts are extensions of Carland's views on race and the "othered." Moraga and Yamada's quotes forefront the issues of (in)visibility that women of color face. Through Moraga, Carland asks her readers to consider a feminism that does not require assimilation into white culture, and to consider the implications and significance of their differences when strategizing the upheaval of oppressive systems. Yamada's quote echoes the sentiment Carland touches upon in "Allowing a Little Class to Leak Out (the puddle under the table)"- - the idea that purposely obscuring the troublesome aspects of life serves only to reiterate the unsolicited power of dominant cultural apparatuses and maintain their oppressive and discriminatory frameworks and practices.

Lorde's excerpt aligns Carland with the larger Riot Grrrl principle of resisting norms. If her readers were familiar with the text from which this quote is taken, they would have understood that Carland is also emphasizing the arbitrariness of gender and cultural norms. Nguyen might read Carland's appropriation of Rich's quote as an expression of her desire for proximity to the non-white racialized "other." However, I believe Carland's appropriation of this quote is more indicative of Cvetkovich's argument. Through this excerpt, and through all of the others as well, she is essentially reiterating her belief that women must continue to voice their experiences in order to keep their realities visible and to destabilize the frameworks of insidious traumas. 
As a whole, these quotes paint the ultimate picture of the feminism in which Carland believes - an organized community effort that can only succeed if it is as inclusive as it is complex. Part of that complexity requires examining from where racism and other forms of discrimination stem. Carland does not find the answer to this question herself, but she does encourage her readers to do so. Instead, she employs these quotes not as an analysis of race but as lines of inquiry. I $\boldsymbol{\vee}$ Amy Carter features two more direct encounters with concepts of race. These instances demonstrate Carland's commitment to women of color and her earnestness to explore the depth of racialization, but they are slightly misguided attempts.

\section{Cecilia Dougherty Reviews Bad Girls West}

In $I \vee$ Amy Carter \#4, Carland features a four-page review of the exhibition Bad Girls West written by her friend Cecilia Dougherty. ${ }^{38}$ In the review, titled "PATHETIC," Dougherty has much to say about the relationship between art, feminist history, and commodification, as well as her observation that Bad Girls West is a microcosm of larger cultural issues surrounding white middle-class society's pitiful attempts at understanding the working-class, the LGBT community, and the experience of people of color. Her review is the only personal account of non-white race in all five issues of I Amy Carter, which is interesting because Dougherty is white. Dougherty and a number of her friends

\footnotetext{
${ }^{38}$ Bad Girls West is the second-half of a two part, bicoastal exhibition. The first show, Bad Girls, was held at the New Museum of Contemporary Art in New York City. Bad Girls West took place in the Wight Art Gallery at the University of California, Los Angeles. The exhibitions featured over sixty visual, performance, and media artists, including men and children. The New Museum describes the show as "dealing with gender issues in ways that are both humorous and distinctly transgressive" (Cahan, Kingsley, and Saad 1994: 7). Cecilia Dougherty is a videoartist, photographer, and writer whose work has been featured internationally since the early 1980s.
} 
were contributors to parts I and II of the Bad Girls exhibitions, so she is particularly critical of what she perceives as the show's failures.

Dougherty's review is more of a long-winded rant. She picks apart Bad Girls West and berates the show's curators, Marcia Tucker and Marcia Tanner, for an endless number of offenses. According to Dougherty, some of the greatest transgressions committed by Tucker and Tanner are that they included the work of men in a feminist exhibition and that they disrespectfully co-opted the term "girl" from black and gay cultures. A subsection in an essay written by Tucker in the Bad Girls catalog also upsets her. This section, as its title "A Hasty Hystery" indicates, is a very brief account of second-wave feminist history. Dougherty claims that Tucker erases the experiences of second-wave feminists of color by not discussing them, but this is not the case. On the contrary, Tucker does not intentionally exclude second-wave feminists of color, rather she acknowledges that the second-wave was predominantly "young, white, middle class, formally educated, and heterosexual" and often naïve about the relationship between feminism and race (Tucker 1994: 15-16).

Rants are not uncommon in Riot Grrrl zines and $I \boldsymbol{\bullet}$ Amy Carter also has its fair share, only they tend to be more sophisticated and better conceived than Dougherty's diatribe. It is not entirely clear why Carland permitted this review. Perhaps she was short on content; maybe she felt obligated to include it because she and Dougherty were friends; she might have even agreed with Dougherty's assessment of the exhibition. However, I think it is likely that Carland included this review because Dougherty spends a fair amount of time highlighting the achievements of feminists of color during the second-wave. I do not believe that Carland would advocate a white woman speaking on 
behalf of women of color, which is effectively what Dougherty does in her review, but she is certainly a proponent of continual learning and Dougherty touches upon some very significant moments in the history of feminists of color. She also reminds Carland's white readers that their unchecked privilege not only impedes the progress of women of color, but the progress of the women's movement as a whole. The final instance of nonwhite race in $I \vee$ Amy Carter reminds her readers of this again.

\section{Co-opting Black Imagery}

Page four of $I \boldsymbol{V}$ Amy Carter \#2 features a smattering of random elements. The top left corner is a list written by Carland that details ten things she finds sexy about girls. The top right is an image of Rosie the Riveter. Situated between these two items is the symbol for female gender $(+)$ topped with a crown. The bottom left is a clipping from the letters to the editor section of Star magazine that praises Hillary Clinton for defending her daughter Chelsea against media chastisement. And the bottom right-my focus here-is a drawing of a finger-pointing African American woman declaring, "If You're Dissin’ The Sisters You Ain’t Fighting The Power!!” (Carland March 1993: 4).

Carland appropriated this image from the political activist group Revolutionary

Communist Party. ${ }^{39}$ It was drawn by an unnamed volunteer artist and it was reproduced as an image in the group's newspaper Revolutionary Worker as well as one of its pamphlets; it was also made into a sticker. ${ }^{40}$ Because the image comes from an

\footnotetext{
${ }^{39}$ When I say "the image" or "the drawing" in this section, I am referring to the drawing of the African American woman and its associated text, "If You're Dissin' The Sisters You Ain't Fighting The Power!!" Carland did not alter the image with this line, it is original to the drawing. ${ }^{40}$ The Revolutionary Communist Party has its own nationwide bookstores, Revolution Books, as well as its own publishing company, RCP Publications. Carland would have had easy access to the organization's Los Angeles bookstore when she was producing I $\boldsymbol{\vee}$ Amy Carter while in graduate school. Information about the use of this image by RCP Publications was provided to
} 
alternative source that is less accessible than mainstream publications, it is likely that many of Carland's readers were not privy to its original context or meaning. Additionally, Carland's take on the drawing is rather vague. It is not contextualized in the zine in any apparently meaningful way, which leaves it open to interpretation.

Based on the other methods in which Carland addresses issues of race as well as the ways in which she analyzes other forms of oppression like homophobia, it is likely that she employs this image in support of intersectionality and to remind her white readers to be mindful of their privilege. However, Carland's use of this image is ultimately a problematic appropriation of the aesthetics and language of black women. This scenario is troubling because it confirms Nguyen's notion of proximity in Riot Grrrl's world of public intimacy. Even if she does not intentionally employ the image in this manner, Carland is still, in effect, aligning herself with the "sisters" therefore diminishing her own whiteness in such a way that exempts her from critiques of racism. Carland's use of this particular image is also questionable because, although women of color make a handful of other appearances in $I \boldsymbol{V}$ Amy Carter, it is the only visual representation of non-white race in all five issues - simply including a smattering of images of women of color is not equivalent to visually representing the concept of race. ${ }^{41}$ This absence is significant because, although she promotes intersectionality textually, the images in her zine minimally reflect racial diversity. In addition, Carland's one visual

me by an RCP Publications representative named Terry in an e-mail message from April 10, 2014.

${ }^{41}$ The images of non-white women in I Amy Carter include a photograph of an African American actress or performer from the early to mid-twentieth century (who I have not been able to identify), a photograph of Audre Lorde, a few photographs of unnamed murder victims, a film still from the movie Times Square with Puerto Rican/Spanish-American actress Trini Alvarado, a drawing of an African American woman on the cover of another zine called Girlhero, and a cartoon of two Portuguese or Brazilian lesbians holding hands. 
representation of the concept of race is tenuous at best. Ultimately, I Amy Carter collapses back into whiteness.

Many zines with longer runs did not undertake the many difficult and serious social problems Carland confronts in only five issues of I Amy Carter. Carland spends plenty of time enthusiastically obsessing over bands and girl crushes, but, as a whole, she also spends an equal amount of time, if not more, musing on issues of gender, sexuality, class, and race. The methods with which she chose to address race are not model efforts, but they are distinct from many of the troubling attempts by other Riot Grrrls that Nguyen discusses in her critique. Although she participates in Riot Grrrl's environment of girl love, Carland does so in a way that does not make the same unreciprocated demands of Grrrls of color. Instead, she encourages her white readers to question their relation to racialized bodies and urges them to support women of color through their actions and by being self-reflexive. She provides statistics that are evidence of the consequences of institutionalized oppression and reiterate claims of racism's deep-rooted existence. She also cultivates various lines of inquiry about how these frameworks are implemented by prompting her readers with the philosophical questions and ideas about race she compiles from reading feminist theory.

Carland's (lack of) visual representation of women of color, however, is problematic. Their appearance is sporadic compared to the images of other women in $I$ Amy Carter and Carland essentially co-opts black cultures of the United States in the one instance where she provides an image that makes a statement about racism. This imbalance reveals a weakness in Carland's self-reflexivity and her application of intersectional feminist philosophies. She is mindful of her white privilege and many of 
the ways in which racism is embedded in mainstream society, but she still struggles with approaching and integrating discussions of race just like many other Riot Grrrls—she is still very much a product of her time. Carland also has difficulty visually representing the effects of class. This is surprising because her personal narratives about life in the welfare-class are so vivid that it is nearly impossible to not be moved by her experiences. In the following and final section of this chapter, I discuss one of Carland's most compelling essays about class and analyze the significance of the few instances in which she articulates the subject visually.

\section{Part III: "REFLECTIONS OF A STUPID SLUT": I Amy Carter and Class}

Nguyen argues that Riot Grrrl's acts of gender deviance are not accessible to all women because in mainstream conceptions, sexuality is not only conflated with gender, it is also conflated with class and race (2012: 179). Riot Grrrl's attempts to reclaim sexual agency, for example, by re-appropriating shame words such as "slut" do not operate the same way for Grrrls of color and the working- and welfare-classes as they do for middleclass white Grrrls. Their bodies have already been inscribed with the negative understanding of these terms by racist and classist frameworks (Nguyen 2012: 179). Carland has suffered the consequences of the conflation of such insidious traumas because she is a (former) member of the welfare-class. Her ruminations on the ways in which her class history affects her sexuality and body image are an insightful analysis of the consequences of institutionalized oppression.

In this section, I ground my analyses in one of Carland's most poignant essays taken from the final issue of $I \vee$ Amy Carter, "REFLECTIONS OF A STUPID SLUT \{or, a frigid feminist - depending on how you look at it\}." In this essay, Carland 
recounts the injustices she witnessed while growing up in government subsidized housing, as well as her own heartrending experiences as a welfare kid. These narratives reveal discrepancies between the lived reality of welfare-recipients and society's perception of them. Similarly to Nguyen, she reflects upon how society's perception of welfare-dependent women has already defined their sexuality for them-including the sexuality of young girls. She also discusses how the commonly held notion that a majority of welfare-recipients are minorities is yet another reflection of the deep-rooted racism in American society. Carland's personal story—expressed textually as well as in the few instances she represents her experiences of class visually - ultimately demonstrates insidious traumas in action. She unites Cvetkovich's vision of the positive capacity of counterpublic spheres with Nguyen's desire that Riot Grrrl examine the structural determinations of oppression to elucidate how dominant culture initiates and then ossifies its discriminatory practices.

\section{The (In)Visibility of Welfare-Dependent Women}

Carland argues that society believes that welfare-dependent women enable their class status because they are dishonest, hypersexual, and stupid. As such, the sexuality of these women is monitored both socially and bureaucratically. In "REFLECTIONS OF A STUPID SLUT \{or, a frigid feminist - depending on how you look at it\}," she discloses how her status as a girl who was welfare-dependent labeled her a slut before she was even sexual —at the age of nine. She reflects on the fact that many of her friends were not allowed to visit her home, or even associate with her because she was effectively marked by her predetermined social and sexual standing and, although she does not mention it, the location of her home- the Section 8 neighborhood (Carland Summer 
1994: 9). She also details many of the instances in which she witnessed the government mediating the sexuality of welfare-dependent women by severely infringing upon their privacy and stripping them of agency over their own bodies.

When she was growing up, Carland's household received random visits from social workers that included intensive rounds of questioning about her mother's personal life, especially if the social worker happened to notice any new purchases. She recalls, "Anything out of the ordinary was suspect and assumed to be connected to a man and not an off the books job. We were taught that my mother's sexuality was to remain invisible and non-existent" (Carland Summer 1994: 9). Carland's mother's body was so marked by preconception that even when she took steps to improve her family's standing, her work ethic was completely undermined by the insinuation that she must have used her body to acquire new things because she could not have earned them through "legitimate" means on her own. Her sexuality was made simultaneously (in)visible — she was not permitted to be sexual, yet her class-status meant sexual depravity was written all over her just the same.

Carland also discusses how the hypersexuality of welfare-dependent womenespecially women of color-is so distorted that many of them were essentially forced to use experimental forms of birth control or be sterilized if they wanted to maintain their benefits. Not a single welfare-dependent man she had known while growing up had ever been subjected to the same treatment in order to maintain his state aid (Carland Summer 1994: 10). ${ }^{42}$ She also comments on the myth of the welfare queen, citing statistics that

\footnotetext{
${ }^{42}$ In addition to forced sterilization and experimental contraception, the federal government further restricted the authority of women on welfare by denying them access to abortions. In 1976, Congress passed the Hyde Amendment which prevented Medicaid from administering
} 
indicate that, contrary to popular belief, white women in rural areas, not women of color, were the largest group of welfare-recipients. She emphasizes that she is not trying to diminish the plight of minority groups, rather she is attempting to complicate the popular image of poverty and demonstrate that the conflation of class and race is just another racist assumption (Carland Summer 1994: 11).

Mothers who stayed in mentally, physically, and sexually abusive relationships were an all-too-familiar circumstance in Carland's world. These women endured abuse because they knew that if they left their toxic relationships they risked losing their children, their residence, and their much-needed welfare benefits (Carland Summer 1994: 10). Many abused children also remained silent because being taken away from their abusive family and put into the system was a much scarier prospect than being subjected to violence at home (Carland Summer 1994: 10). The disturbing reality of these situations is exemplified by the story of a lesbian mother Carland knew as a child who lost custody of her children to her sexually abusive ex-husband because she had been outed. If that woman had never left her abusive ex and had stayed closeted, she would not have had to worry about losing her children (Carland Summer 1994: 10). The stories of these mothers contradict widely held notions that poor women stay in abusive relationships because they are too dumb to leave. These women risk losing everything when they try to escape.

financial aid for abortions except in cases of incest or rape or if the mother's life was endangered. In 1980, this amendment was upheld by the Supreme Court in the court case Harris v. McRae (NCHLA 2008: 1). 


\section{Expectations of the Poor}

In “REFLECTIONS OF A STUPID SLUT \{ or, a frigid feminist - depending on how you look at it\}" Carland also discusses the expectations people have of her and her family once she has been "outed" (voluntarily or involuntarily) as a member of the welfare-class, especially where serious domestic issues are concerned. She shares:

I've actually had friends say to me that it's easier for me to deal with my abuse history and the effects it's had on my family than it is for them to deal with their issues. In other words my family is supposed to be drunk, abusive, and violent but their upper middle class families are not supposed to - so therefor I have less of a stigma to overcome, because I am 'less than' to begin with. Fucked up. (Carland Summer 1994: 10; emphases original)

People's conception of Carland's welfare-marked body does not even afford her the luxury to express what she has had to endure.

Carland is also perturbed by her involuntary shift from welfare- to middle-class since leaving her life in Maine to pursue higher education and her work as an artist. She writes:

I've been told that I am now middle class. And this isn't about financial security, because I have none. This is about notions of assimilation. Just because I know some big words and don't have the same accent I grew up with and I am 'so different' from the rest of my family I have apparently breezed into civilized respect and personal integrity. (Carland Summer 1994: 12)

Carland is resistant to this change because it obscures the reality of the welfare-class by erroneously implying that class-status is a matter of intelligence and civility, not financial assets, which in turn insinuates that anything less than middle-class is equivalent to ignorance and barbarity. She is also wary of this shift because it erases her history. She does not want to forget where she comes from and she does not want to sever the connection she shares with the women in her family. Although she will never be able to 
expunge this history from her own memory, she could easily prevent the judgment of other people by neglecting to mention it — but she does not do this. Instead, she embraces her impoverished past with all of its flaws and pain and she uses her memories to reveal insidious attempts to silence the oppressed.

The infractions enacted on the lives of welfare-dependent women reveal how dominant society uses the government to initiate and then perpetuate the normalizing frameworks that mark their bodies. Carland's first-person account in "REFLECTIONS OF A STUPID SLUT \{or, a frigid feminist - depending on how you look at it\}" reveals how the mainstream believes that these women occupy their social positions by choice. They are cast as lazy, stupid, hypersexual deviants who could move up in society but elect not to. In effect, the mainstream treats class as a symptom that can be overcome if only these women had integrity. As belittling as this notion is, it perpetuates false hope; welfare-dependent women will never be allowed to escape the roles into which they have been typecast because dominant culture has been able to successfully conceal the institutionalization of misogynistic classist and racist practices. It has also embedded these practices into popular culture.

\section{Visual Representations of Class}

When Carland was growing up, television shows like The Brady Bunch offered models of morality for American families; but the Bradys' upper-middle-class lifestyle and perpetually cheerful home were nothing like the life she was living. She recalls how there were not any heroes or mentors in popular culture that spoke to her specific social position: 
No one on television (or in the movies I saw or the books I read) was on welfare. I never saw an image of someone going to the store with food stamps and being humiliated by other kids and sometimes adults. I never saw a mom begging some social worker for a medical voucher to take her child to the dentist. The closest thing I had to my reality was 'Good Times' but they still weren't as poor as us. (Carland Summer 1994: 10-11)

It is difficult to imagine who or what Carland would envision as a welfare-class role model because she does not offer any examples. But perhaps this is because she felt that the standard images of the welfare-class were not appropriate - there was no source available to her from which she could conjure her own vision. Regardless, I think her bigger concern was that because her experience was invisible, many people continued to believe that the disparaging stereotypes about the welfare-class were true. Carland's narrative complicates preconceptions about welfare-recipients but she has difficulty representing her experience and her feelings toward classism visually.

There are very few instances in which Carland visually articulates class in $I$ Amy Carter. In issue \#1 she shares a single panel that she appropriated from a comic strip that functions as a tongue-in-cheek commentary about the upper-class. The image depicts an older white man dressed in a business suit who raises a martini while exclaiming, "I have ascended to a position that does not require profound thought!" (Carland December 1992: 14). Through this cartoon Carland is essentially criticizing the upper-class, implying that their money and high social status make them self-absorbed and ignorant. The other visualizations of class in $I \boldsymbol{V}$ Amy Carter speak to how lack of knowledge about the circumstances of the underprivileged influences how they are perceived in some very unfair and detrimental ways. 
Dominant culture projects an over-simplified image of the poor-it pays no heed to the lived complexities of their day-to-day lives. It does not acknowledge what it is like to be the bearer of shame or what it is like to be automatically labeled "less than" and be treated accordingly. Carland complicates this image by sharing her story, but she also highlights some of the consequences of stereotypical notions of the poor by emphasizing some of the terms used to describe them. In I $\boldsymbol{\bullet}$ Amy Carter \#3, Carland discusses an activist art project that took on the issue of "NHI" (no humans involved) cases. ${ }^{43}$ This group of artists used their work to protest and document the unsolved murders of fortyfive women in San Diego County, California (Carland Summer 1993: 15-16).

Carland pastes excerpts from their book, including one that explains "these women, designated by law enforcement as prostitutes, drug addicts, and transients, have been associated with the police term, 'NHI—no humans involved"' (Carland Summer 1993: 16). Police dehumanized these women further by designating their cases "misdemeanor murders." A mother of one of the murdered women, Anna Lucilla Varela, elaborates on the callousness of the police by describing how they never called her daughter by her name; they only ever referred to her as "the prostitute." Because of their social status, these women were rendered invisible even after they suffered violent deaths; but Carland restores their identities as well as their humanity by listing each and every one of their names in her zine. This gesture is simple but even now, twenty-one years after this issue of $I \vee$ Amy Carter was created, these women retain some semblance of visibility. Carland enacts a similar tactic concerning words with which she herself has been labeled as result of her social status.

${ }^{43}$ The artists involved in this project were Deborah Small, Elisabeth Sisco, Scott Kessler, Carla Kirkwood, and Louis Hock. 
Bracketing the revised version of Carland's essay "Allowing a Little Class to Leak Out (the puddle under the table)" in I Amy Carter \#4 are two columns that list sixteen words that Carland was called before she was ten years old: LAZY, SHIFTLESS, FELON, DRUNK, INBRED, REDNECK, TRASH, SCUMBAG, IGNORANT, DIRTY, STUPID, WELFARE CASE, FILTHY, BASTARD, HICK, and SLUT (Carland January 1994: 27-28). Although these words are not strictly images, they are presented visually. By setting them apart from the body of her essay and further emphasizing the words by giving each its own black frame and typing them out in all capital letters, Carland presents her readers with the opportunity to consider each term on its own. Estranged from their original context, the magnitude of using such words to describe another person—especially a child—really sets in. Stereotypes about poor people have become so distorted by insidious practices that children are labeled disparagingly without ever having had the chance to become their own person.

This is the pattern of insidious traumas. They operate unnoticed and unquestioned for so long that their oppressive and discriminatory frameworks are subsumed into the mainstream where they continue to be reiterated until the people who these practices adversely affect band together and point to their experiences as evidence that something is terribly wrong. These frameworks are so powerful that they obfuscate the nuances of lived experiences with "official histories," effectively alienating countless numbers of people. Forced to operate outside of sanctioned realms, the alienated form counterpublic spheres where their stories are allowed to be told. These dialectical spaces not only afford visibility, they also function as archives where testimonies, now made 
tangible, can be stored and serve as alternative modes of knowledge instead of forcibly erased.

By sharing the story of her transgressive identity through $I \vee$ Amy Carter, Carland ensures that her history and her realities are not erased. I Amy Carter also serves as the model for which Carland so desperately searched when she was growing up. Girls like her who have endured so much at the hands of discriminatory and oppressive frameworks now have something to hold on to in their own times of need. They have something to give them the strength needed to converse with the effects of their lived experiences and to touch the parts of their hearts that hurt; something to show them how they can be happy even if parts of their being are broken; something to inspire them, as Le Tigre would put it, to keep on livin'. 


\section{CHAPTER V}

\section{EPILOGUE}

When I began the preliminary research for this project, I was enthralled by the volume of Riot Grrrl zines in existence but also completely overwhelmed. Luckily, I found salvation in Karen Green and Tristan Taormino's book A Girl's Guide to Taking Over the World: Writings from the Girl Zine Revolution (1997). This book is a combination of textual and visual excerpts from Riot Grrrl era girl zines, interviews with girl zine creators, and a handful of short compositions about feminist zine culture written by its participants. Amongst this compilation of 1990s feminist subculture is where I first discovered Tammy Rae Carland. I was instantly captivated by her after reading the essay she wrote for this book, titled "Read It and Weep (or Laugh)," and then fully committed to writing about I $\bullet$ Amy Carter once I read the three passages — "Girl Talk," "Reflections of a Stupid Slut \{or, a frigid feminist - depending on how you look at it \}," and "Girls with Guns"- that Green and Taormino selected from her zine. I found Carland's writing articulate, intelligent, and honest—she could have certainly written for a highly regarded mainstream publication at the time if she were so inclined-and I was charmed by her lively sense of humor.

In full disclosure, I was also drawn to Carland because of her personal history. Her frankness concerning class and other aspects of her personal life parallel instances in 
my own family history that have never really been discussed outside of our tightly knit circle. I have never been explicitly instructed to stay mum on our business, but neither has anyone else in my family ever truly engaged in dialectical conversations about it. I have also always felt that some of these stories were not mine to tell and, in cases where I felt open discussion was warranted, I often hesitated to speak openly, stifled by an everpresent sense of (undue) shame. Carland's unapologetic candor about her troubling personal experiences with class and abuse — and also sexuality and gender — and the eloquence with which she discusses these topics was a first for me. Needless to say, I felt compelled to further investigate how she addresses issues of gender, sexuality, class, and race visually and textually in $I \vee$ Amy Carter from her unique perspective. Analyzing Carland's approach to cultural critique and identity formation from her specific social position also made way for a certain level of my own self-reflexivity and growth as a twenty-first century feminist and a student of visual culture.

\section{Thesis Goals, Conclusions, and Future Projects}

Employing visual culture as my lens to examine the visual and textual elements of I Amy Carter, I set out to achieve three goals in writing this thesis: to emphasize the significance of the zine as alternative press; to perpetuate the discussion of the sociocultural issues Carland begins to address in I Amy Carter; and to continue and broaden the conversation about issues within Riot Grrrl culture itself. Along the way, I gained new knowledge in a number of areas. I discovered the zine subculture; I unearthed information about the social and political history of the United States that I had not previously been aware of; I learned about the less attractive side of Riot Grrrl culture; and 
I came across a relatively new field of academic discourse—white trash studies—with which I plan to expand my project in the future.

The Significance of Zines as Alternative Press

Because zines are independently produced by everyday people and lack the glossy, flawless aesthetic of mass-produced media, they are hardly ever taken seriously by anyone other than their producers and the people who are emphatically committed to them. It is true that anyone with the inclination can create a zine and it is not entirely wrong to be wary of this fact-large-scale publications come equipped with professionally trained researchers, writers, editors, and fact-checkers; zines do nothowever, it is also important to recognize the significance of the zine-as-medium and the underlying reasons a person is compelled to create an alternative publication in the first place. Texts about zine culture, including Stephen Duncombe's Notes from Underground (1997), Piepmeier's Girl Zines: Making Media, Doing Feminism (2009), and Green and Taormino's A Girl's Guide to Taking Over the World: Writings from the Girl Zine Revolution (1997), reveal that many people are driven to create zines because they have been ostracized by popular culture. For many zinesters, especially Riot Grrrls, being dismissed by dominant culture only fueled their already heated passion.

Zines provide physical documentation of the events and lives that are forced to operate outside of normative society because they are made compulsively invisible by domineering recitations of the past. As time progresses and distance is placed between an event and the person or group it affects, memories begin to dissolve losing an already fleeting grasp on the moment. Material artifacts such as zines are akin to snapshots taken at the time these events occur, archiving as tangible evidence lived testimonies that are 
expressed through imagery and writing. As the years carry on, the zine as alternative source - stowed away by creators, readers, and, increasingly, archival institutionspreserve the people and the stories that would otherwise fade away beneath the shadow of normalizing oppressive frameworks.

As people move on with their lives, their interests, concerns, and priorities shift. For example, many of Riot Grrrl's original members likely do not identify as such any more. That is why their zines, as alternative primary sources, are so significant. They detail firsthand the contemporary experiences and beliefs of a movement of subjugated women — details that become increasingly difficult to recall over time. The dedicated zine community is the reason why I, and other scholars, am afforded the opportunity to reflect upon the ways in which Riot Grrrls responded to the socio-cultural crises of the United States in the 1980s and early 1990s. Through I Amy Carter, Carland provides a wellspring of information that is untainted by outsiders, a perspective that comes straight from the source rather than having been predigested by those who are removed from Riot Grrrl and then served up in a book or an article with variable underlying objectives.

Regardless of intent, every tale that is told about a past event is skewed in one way or another. These stories and their perpetuation are affected by the personal and the political and, as a result, are censored or exaggerated along the way. But the fact is that it is impossible to be apprised of the particularities in the lives of every group of people, let alone each individual on Earth. We will never be able to fully grasp the breadth of consequences generated by culture's actions or lack thereof-but alternative archives such as zines offer a good place to start. I Amy Carter, in particular, offers a window into its contemporary cultural moment and the life of its creator. Zines provide a 
wonderful basis from which to both continue and initiate new and innovative dialogue about history and culture.

Perpetuating the Discussion of Carland's Contemporary Social Issues and Broadening the Discourse on Riot Grrrl Culture

Many of the topics Carland touches upon in her zine- the shaming of the female body, arbitrary perceptions of class, ignorance concerning various forms of privilege, and so on—are issues with which we still struggle decades after she created the first issue of $I$ $\checkmark$ Amy Carter. The longevity of such social problems speaks to the force with which they are embedded into our culture. Today, more than ever, oppression is obfuscated by the fallacious idea that the west has successfully moved past its ugly sexist, homophobic, classist, and racist history. Although it is true that as a society we have progressed in many ways, there is still a lot of work to be done with regard to social inequity. As both Riot Grrrl and Carland would argue, silence is equivalent to complicity and this thesis is just one way for me to speak out against inequality and to contribute to the expansion of social consciousness.

As a material artifact of Grrrl culture, $I \vee$ Amy Carter is a tangible expression of the movement's politics and, therefore, also serves as a convenient case study. Nguyen paints an unflattering picture of Riot Grrrl's environment of girl love when she makes the claim that the public acts of intimacy required to be a part of the movement are disproportionately demanding of Grrrls of color and, by extension, Grrrls of the workingand welfare-classes. She believes that under the guise of sisterly solidarity and the unwarranted belief that proximity, or intimacy, with the "other" negates the effects of privilege, these Grrrls are ultimately burdened with the responsibility of educating 
(upper- and middle-class) white Grrrls about what it is like to be a minority, effectively taking on the brunt of the labor by stamping out their ignorance for them. Nguyen maintains that the only ones who benefit from this relationship are (non-poor) white Grrrls as they believe that their moral quandaries have been alleviated in their attempts to truly get to know the "other." In the meantime, Grrrls of color and/or the working- and welfare-classes are left with the real struggle of explaining to their (often unreceptive) counterparts why their approach to racism and class-status is misguided while simultaneously continuing to battle oppression in its institutionalized forms.

The issues within Riot Grrrl culture that Nguyen identifies are unquestionably troubling and real. However, she leaves no room for the positive effects of girl love and acts of public intimacy. Cvetkovich argues that acts of public intimacy can aid in the development of counterpublic spheres which, in turn, can benefit those affected by insidious forms of trauma such as sexism, homophobia, classism, and racism. This is the type of environment of girl love that Carland seeks to generate within $I \vee$ Amy Carter. While Nguyen maintains that Riot Grrrls' insistence on sharing personal stories is burdensome, Cvetkovich believes that it can be a constructive cathartic process, especially where addressing the consequences of insidious practices are concerned. She asserts that public acts of intimacy encourage people with similar affective experiences to come together and formulate an arena in which they can express their truths without fear of negation or being forced to overcome their experiences. These acts are significantly different from clinical treatments of insidious traumas - wherein the affects of traumatic experiences are treated as a medical symptom that must be reconciled - which only perpetuate the invisibility of oppressive practices. 
Cvetkovich suggests that it can be advantageous to publicly articulate these affects through writing, art, performance, etc. because these forms of expression give what was once an intangible memory palpable substance. Now made physically material, these memories can be archived and then serve as the alternative evidence needed to overthrow discriminatory frameworks. So, although Carland relies heavily upon testimony in $I \bullet$ Amy Carter she does not utilize it as an indication of her lack of racism or to distance herself from privilege. Instead, she employs $I \bullet$ Amy Carter as a counterpublic sphere to point to insidious practices at work by means of sharing her personal stories (and the stories of a few of her friends) through original and appropriated visuals and text.

Carland did not pressure other Grrrls for testimony, nor did she use shame or a desire for intimacy with the "othered" as a means to overcome issues of race, class, homophobia, or sexism. In fact, the only thing Carland ever insisted her friends and readers do was share stories about Amy Carter and speak out about inequality_-but even these instances are more akin to gentle encouragement as opposed to demands. The material Carland included in $I \bullet$ Amy Carter reveals a lot about her history and personality. Some of what she shared was downright hilarious, some of it was gutwrenching, but all of it served a purpose. At the time she produced this zine, Carland adamantly believed that knowledge is power. By sharing text and imagery that divulged, for example, personal narratives about issues such as the perception of the welfare-class, opinions about the source of detrimental body images, statistics and hard facts concerning the AIDS epidemic, resources about self-defense - the list goes on and on - she not only added to the corpus of knowledge, she expanded its definition, encouraging others to do 
the same. Carland dedicated three years of her life meticulously handcrafting each issue

of $I \bullet$ Amy Carter all in the name of enacting positive change. Her tactics were not always perfect, but she was open to criticism and wholly invested in her cause.

\section{Future Directions for Analyzing Riot Grrrl Culture and I $\bullet$ Amy Carter}

At one of my final thesis meetings, my committee and I engaged in a fruitful conversation about the directions with which I could continue my research, opening up an entirely new and exciting venue of exploration. We discussed how Carland labels herself white trash and how that term and its implications affect her relationship to gender, sexuality, and both white and class privilege. The fact that both Carland's family and my own are either hesitant to discuss our welfare-class, white trash histories or lack the vocabulary to address them demonstrates, of course, a larger cultural symptom but, more specifically, it also reveals another level of shortsightedness within the Riot Grrrl community — an area that has also not yet been seriously addressed by academics. The glaring issue for which Riot Grrrl is most often cited is its approach to race and white privilege. However, the movement also struggled with the ramifications and representation of class - its presence is almost imperceptible on the Riot Grrrl radar. ${ }^{44}$

Carland was very much a product of her generation and social status, a fact that is made evident when, in the pages of her zine, she attempts to manage the shift in feminist consciousness from essentialist to intersectional. Like many Riot Grrrls, Carland was eager to integrate intersectional feminism into her creative and every day practices but she struggled particularly with navigating issues of race and class. She was also

\footnotetext{
${ }^{44}$ Marcus notes that although some Grrrls came from working- and welfare-class families their struggles were rarely discussed (2010: 121). She also identifies only three Riot Grrrls that addressed class issues in their zines-Mary Fondreist, Erika Reinstein, and Ananda La Vita —all of whom openly criticized Grrrls, and others, who ignored class privilege.
} 
simultaneously affected by her transition into adulthood as she struggled to grapple with an identity that diverged from the norm. However, Carland's unique social positionwhite, welfare-class, feminist, dyke - played a key role in her ability to incorporate intersectionality more successfully than other Riot Grrrls. Many Grrrls had only one trait that prevented them from obtaining a position that permitted authority in dominant society - their gender. Carland, however, endured many more obstacles. Not only was she discriminated against because of her gender, she also suffered because of her sexuality and social class. In addition, her status as white trash intensified her invisibility, pushing autonomy, respect, and authority even further out of her reach but also imbuing her with a deeper understanding of the struggles of Grrrls of color that middle- and upper-class white Grrrls would never be able to understand. It is true that it is easier to hide a white trash identity than it is to conceal the color of one's skin, but the ramifications of this stigma are oftentimes just as harsh when it is exposed.

White trash studies emerged in the early 1990s. It is an interdisciplinary field that draws upon a number of subjects for its theoretical and methodological approach including history, sociology, literature, and anthropology, and at its basis seeks to answer what the concept "white trash" signifies. In the introduction to his book Not Quite White: White Trash and the Boundaries of Whiteness (2006), Matt Wray characterizes the label white trash a "stigmatype" (or a stigmatizing stereotype), which operates as "an expression of fundamental tensions... between the sacred and profane, purity and impurity, morality and immorality, cleanliness and dirt" (2006: 2). He argues that the two components of this slur, the words "white" and "trash," "must be kept apart in order 
to establish a meaningful and stable symbolic order" - an order whose guidelines can be traced back to the tension between race and class (Wray 2006: 2-3).

Wray argues that the stigmatype white trash conflates two terms that, according to norms in the U.S., are intended to be polar opposites. He asks an important question, writing "white... appears as an ethnoracial signifier, and trash, a signifier of abject class status... Which word is the modifier and which the modified?" (Wray 2006: 3; emphases original). White trash studies asks many more questions than this, veering into complex histories and social relations, but this is the sort of question I feel Riot Grrrl should have asked. It is also the type of question I feel can be applied to my future analyses of $I$ Amy Carter.

If, as Wray suggests, the term white trash points to an aberrant divergence from what whiteness is really supposed to be - clean, moral, and right; free of impurities; in a word, untainted by color - then how does Carland's relationship to racialization change because she is white trash? How can I apply the tension between these two signifiersthe ethnoracial "white" and abject class "trash" - to better understand Carland's struggles with representing concepts of race and her class status verbally and especially visually? Carland includes quotations in $I \boldsymbol{\vee}$ Amy Carter from the writing of Dorothy Allison - an author who is renowned for her writing on the experiences of white trash-which is a link that definitely requires exploration, but what other types of visual and verbal lexicons exist that articulate these experiences? How can these vocabularies be employed to help better express the experiences of these groups and help eradicate their associated stigmatypes? More broadly, if Riot Grrrls had attempted to understand stigmatypes such 
as these, how would it have affected their brand of feminism? This single slur and its associated field of study will, undoubtedly, add a significant layer to my project.

\section{Final Thoughts}

We are generally taught to believe that History (with a capital " $\mathrm{H}$ "- the domineering Eurocentric recollection of humanity's collective past) is a linear series of unwavering facts - an anthology of life on Earth preserved for the sake of our everpressing desire to achieve an advanced and enlightened state of being. We are supposed to look back on History, celebrate our achievements, learn from our mistakes, and progress forward. But this type of History is really only a record of a small sample of experiences, and it is composed of content whose scope not only regularly shifts with time but has also been heavily influenced by innumerable factors such as politics, culture, and especially the (im)balance of authority. A person's station in society-determined by gender, sexuality, class, race, religious beliefs, and so on - profoundly impacts not only her or his life experiences but also her or his relationship to this History. In the west, the chronicles of the people who fall outside of the normative confines of the upperclass, straight, white, male will almost always suffer the fate of Historical invisibility. The bearer of power has the upper-hand and will always be able to choose the way History is written and remembered. That is why what is not acknowledged or addressed by those who wield the majority of authoritative power in society is oftentimes just as vital as the barrage of facts and truths we are bombarded with on a daily basis.

The recitation and preservation of history is perhaps most marred by the element of time and its reliance upon recollection. As each new day approaches it leaves a trail of destruction in its wake. People — along with their interests, beliefs, and desires—return to 
the dust from which all aspects of life were created, making way for the inevitable rush of the future that arises from the swirling particles of our past. The result of such an unrelenting, often chaotic process can be beautiful but oftentimes it still carries remnants of the decay from which it emerged. Although people are inclined to believe so, the future is never really new-it will always bear traces of the soot from which it was born. That is why looking to the cracks and recesses of society, where its dirt and grime is allowed to gather - the same place where zines thrive—-is key in beginning to understand how the world really works. As Tammy Rae Carland and I Amy Carter show, life is not always as perfect as we would like it to be, but that does not mean there is no light to be found. 


\section{REFERENCES}

Beegan, Daniel. 1985. "Studds Says Reagan Has Shown Little Concern Over AIDS." The Associated Press, September 19, 1985. http://www.apnewsarchive.com/ 1985/Studds-Says-Reagan-Has-Shown-Little-Concern-Over-AIDS/id-f985ab6ba 6d6fc4ff37ebb0ba0aa657b.

Blush, Steven. 2010. American Hardcore: A Tribal History. Port Townsend, Washington: Feral House. Ebook Library (Accession number: milner.1550864).

Bronski, Michael. 2011. A Queer History of the United States. Boston: Beacon Press.

Burk, Martha. 2004. “Time to Bury Reagan's Legacy for Women.” Women's E-News, June 11, 2004. http://womensenews.org/story/commentary/040611/time-buryreagans-legacy-women\#.UMWGA5Pjk3e.

Cahan, Susan, Kingsley, Evan, and Aleya Saad, eds. 1994. "Bad Girls." In The New Museum of Contemporary Art 1992-1994. New York: The New Museum of Contemporary Art.

Carland, Tammy Rae. 1993. "Allowing a Little Class to Leak Out (the puddle under the table)." Kathleen Hanna Papers; MSS 271; Box 1; Folder 21; Fales Library and Special Collections, New York University.

Carland, Tammy Rae. "Bio." Tammy Rae Carland. http:/www.tammyrae carland.com/bio.htm.

Carland, Tammy Rae. December 5, 1992. I $\bullet$ Amy Carter, Issue 1. From the private collection of Jin Lee.

Carland, Tammy Rae. March 15, 1993. I $\bullet$ Amy Carter, Issue 2. From the private collection of Jin Lee.

Carland, Tammy Rae. Summer 1993. I $\bullet$ Amy Carter, Issue 3. Tammy Rae Carland Riot Grrrl Collection; MSS 290; Box 1; Folder 100; Fales Library and Special Collections, New York University. 
Carland, Tammy Rae. January 1994. I $\bullet$ Amy Carter, Issue 4. From the private collection of Jin Lee.

Carland, Tammy Rae. Summer 1994. I $\bullet$ Amy Carter, Issue 5. Tammy Rae Carland Riot Grrrl Collection; MSS 290; Box 1; Folder 102; Fales Library and Special Collections, New York University.

Carland, Tammy Rae. 1997. "Read It and Weep (or Laugh)." In A Girl's Guide to Taking Over the World, edited by Karen Green and Tristan Taormino, 22. New York: St. Martin's Griffin.

Carland, Tammy Rae, and Ann Cvetkovich. 2012. "Ann Cvetkovich and Tammy Rae Carland in Conversation." From Queer Conversations on Culture and the Arts, California College of the Arts, September 28, 2012. YouTube videos, Parts 1-7: http://youtu.be/YV-6nDvPBaM?list=UUdlYaj_m2AZbr7Z1mUqIlCQ; http://youtu.be/XewlEqN1KLA?list=UUdlYaj_m2AZbr7Z1mUqIlCQ; http://youtu.be/xMICIgjj988?list=UUdlYaj_m2AZbr7Z1mUqIlCQ; http://youtu.be/F26dHCmL-Z0?list=UUdlYaj_m2AZbr7Z1mUqIlCQ; http://youtu.be/zpOs0yhMDGQ?list=UUdlYaj_m2AZbr7Z1mUqIlCQ; http://youtu.be/XWttzLKlu2o; http://youtu.be/XWttzLKlu2o?list=UUdlYaj_m2AZbr7Z1mUqIlCQ.

Centers for Disease Control and Prevention (CDC). 2010. "HIV Among Women." Last updated March 6, 2014. http://www.cdc.gov/hiv/risk/gender/women/facts/ index.html.

Centers for Disease Control and Prevention (CDC). 2010. "Leading Causes of Death by Age Group, Black Females-United States, 2010.” http://www.cdc.gov/women/ lcod/2010/WomenBlack_2010.pdf.

Centers for Disease Control and Prevention (CDC). 2010. "Leading Causes of Death by Age Group, Hispanic Females-United States, 2010.” http://www.cdc.gov/women/ lcod/2010/WomenHispanic_2010.pdf.

Cvetkovich, Ann. 2006. An Archive of Feelings: Trauma, Sexuality, and Lesbian Public Cultures. Durham and London: Duke University Press.

Dunn, Kevin, and May Summer Farnsworth. 2012. "We ARE the Revolution": Riot Grrrl Press, Girl Empowerment, and DIY Self-Publishing." In Women's Studies: An inter-disciplinary journal, Volume 41, Issue 2: 136-157. doi: 10.1080/00497 878.2012.636334.

Eaklor, Vicki L. 2008. Queer America: A GLBT History of the $20^{\text {th }}$ Century. Westport, Connecticut: Greenwood Press. 
Faludi, Susan. 2006. Backlash: The Undeclared War Against American Women. New York: Three Rivers Press.

Farnsworth, May Summer, and Erika Reinstein. 1993. "Riot Grrrl Press: Six Reasons Why Riot Grrrl Press is Important RIGHT NOW!” Johanna Fateman Riot Grrrl Collection; MSS 258; Box 1; Folder 49; Fales Library and Special Collections, New York University.

Fields, Jill. 2012. "Frontiers in Feminist Art History." Frontiers: A Journal of Women's Studies Volume 33, Number 2: 1-21. doi: 10.1353/fro.2012.0032.

Francis, Roberta W. "The History Behind the Equal Rights Amendment." The Equal Rights Amendment. http://www.equalrightsamendment.org/history.htm.

Jones, Amelia. 2000. “"Post-Feminism'-A Remasculinization of Culture?” In M/E/A/N/I/N/G: An Anthology of Artists' Writings, Theory \& Criticism, edited by Susan Bee and Mira Schor, 7-23. Durham and London: Duke University Press. EBSCOhost Humanities International Complete (Accession number 18652809).

Marcus, Sara. 2010. Girls to the Front: The True Story of the Riot Grrrl Revolution. New York: Harper Perennial.

Mauer, Marc. 2013. “The Changing Racial Dynamics of Women's Incarceration. The Sentencing Project. http://sentencingproject.org/doc/publications/rd_Changing\% 20Racial\%20Dynamics\%202013.pdf.

National Committee for a Human Life Amendment (NCHLA). 2004. "Human Life Amendment Highlights: United States Congress (1973-2003)." National Committee for a Human Life Amendment. http://www.nchla.org/datasource/ idocuments/HLAhghlts.pdf.

National Committee for a Human Life Amendment (NCHLA). 2008. "The Hyde Amendment." National Committee for a Human Life Amendment. http://www.nchla.org/datasource/ifactsheets/4FSHydeAm22a.08.pdf.

Nguyen, Mimi Thi. 2012. "Riot Grrrl, Race, and Revival." Women \& Performance: a journal of feminist theory Volume 22, Issue 2-3: 173-196. doi: 10.1080/ 0740770X.2012.721082.

The Punk Singer. Directed by Sini Anderson. IFC Films, 2013.

Spencer, Amy. 2005. DIY: The Rise of Lo-Fi Culture. London and New York: Marion Boyars. 
Tucker, Marcia. 1994. "The Attack of the Giant Ninja Mutant Barbies." In Bad Girls, 14-46. Cambridge, Massachusetts: The MIT Press.

Vasquez, Tina. 2013. "Revisiting the Riot: An Interview with Punk Veteran Mimi Thi Nguyen." Bitch 59: 39-43. EBSCOhost Academic Search Complete (Accession number 87645520).

Wallis, Claudia, Brown, Scott, Ludtke, Melissa, and Martha Smilgis. December 4, 1989. "Onward, Women! The Superwoman is Weary, the Young are Complacent, but Feminism is Not Dead. And, Baby There's Still a Long Way to Go." Time Volume 134, Issue 23: 80-89. EBSCOhost Academic Search Complete (Accession number 57900854).

WGBH Educational Foundation. 2010. "People \& Ideas: Jerry Falwell.” PBS: Frontline and American Experience. http://www.pbs.org/godinamerica/people/jerryfalwell.html.

Wray, Matt. 2006. "Introduction: White Trash as Social Difference." In Not Quite White: White Trash and the Boundaries of Whiteness, 1-20. Durham, North Carolina: Duke University Press.

Zinn, Howard. 2005. A People's History of the United States: 1492-Present. New York: Harper Perennial Modern Classics. 